\title{
RECONOCIMIENTO ARQUEOLÓGICO EN LOS VALLES CERGANOS A LAS MARGARITAS, CHIAPAS
}

\author{
Carlos Álvarez \\ Centro de Estudios Mayas \\ UNAM
}

Este proyecto intenta conocer el patrón de asentamiento prehispánico en la región de Las Margaritas, comparándolo con asentamientos coloniales y modernos; aspecto que considero importante para el estudio de problemas demográficos y de movimientos de población, en la zona tojolabal de los Altos de Chiapas y en el área Chuj de los Cuchumatanes de Guatemala.

Una parte de la poca información que se conoce se encuentra principalmente en las obras de Blom y La Farge (1926) y Palacios (1928); estos autores describen cinco zonas arqueológicas con arquitectura monumental e inscripciones jeroglíficas, denominadas: Hunchabin, Chinkultic, Tenam Puente, Tenam Rosario y Santa Elena Poco Uinic. Estos grandes centros mayas pueden ser considerados como el único foco de atención respecto a la arqueología de la zona tojolabal.

Todos los trabajos arqueológicos que se han realizado en esta zona, se encuentran en áreas vecinas a la región de Las Margaritas. Se puede señalar que no se conocen en la literatura arqueológica menciones o descripciones, por breves que éstas sean, acerca de la arqueología de los valles cercanos a la población de Las Margaritas, centro principal de los indígenas tojolabales.

Con base en la información obtenida por otros investigadores del Centro de Estudios Mayas, acerca del grupo tojolabal, surgieron varias interrogantes que fundamentaron un proyecto arqueológico en esta zona.

En primer término, qué situación geográfica tuvo ēste grupo étnico durante la época prehispánica y cuál es la antigüedad de sus asentamientos; y estrechamente ligada a la cuestión anterior, surge la pregunta de si los tojolabales son originarios de esta región y por 
consiguiente los constructores de las zonas arqueológicas o llegan en una época posterior provenientes de otras regiones.

\section{Delimitación del área de estudio en el campo}

El área de estudio del proyecto se encuentra dentro de la zona geomorfológica del Estado de Chiapas denominada Las Montañas de Oriente o la Serranía de Lacandonia (Mulleried; 1959).

Respecto a la geología de Las Montañas de Oriente se puede decir que afloran en diversos lugares de la región los estratos marinos de mesozoico superior y del terciario inferior y medio con gran abundancia de fósiles; sobre estos estratos marinos hay depósitos superficiales del cuaternario; así como los suelos lateríticos producto de la acción climática. También aparecen al este y el oeste de Las Margaritas grandes mantos de rocas calizas claras (Mulleried; 1959). (Helbig; 1976).

La región de Las Margaritas se localiza en el extremo oriental de la meseta de Comitán y presenta una altitud variable entre los 1,400 y 1,700 metros sobre el nivel del mar. El clima puede considerarse templado subhúmedo con temperaturas promedio de $18^{\circ} \mathrm{C}$ y $20^{\circ} \mathrm{C}$ en las partes montañosas más elevadas. Existen en la región dos variantes climáticas principales que se localizan una en la meseta de Comitán y en las zonas que rodean a la meseta de San Cristóbal por debajo de los 2,000 metros sobre el nivel del mar y la otra aparece en la Serranía de la Independencia (Orellana; 1978).

Las variaciones en la vegetación de las tierras templadas y frías de Chiapas, están sujetas a diferentes factores como: la constitución del suelo, el grado de humedad y la temperatura que varía con la altitud y la exposición solar (Miranda; 1952).

Respecto a la vegetación se puede decir que prevalecen en la región dos tipos:

a) Bosque bajo deciduo con vegetación secundaria de gramíneas o hierbas que se encuentra principalmente en los alrededores de Las Margaritas.

b) Generalizado por toda la región bosque mixto de pinos y encinos, hasta sus límites con el bosque deciduo característico de la región de Los Lagos de Montebello (Helbig; 1976: mapa 8) (Láms. 1-2).

Otra característica importante de la vegetación de esta región, que se debe al ambiente frío y húmedo durante el año, a causa de la protección de las nieblas nocturnas, es la gran abundancia de 
orquídeas, aráceas y bromeliáceas epífitas, algunas de gran belleza (Miranda; 1952: 135).

El área propuesta teóricamente para el proyecto cubre desde la serranía divisoria entre Comitán y Las Margaritas por el oeste, la parte nororiental del Municipio de La Independencia por el sur y el borde de la serranía del Yalhuitz con la cañada de La Soledad por el norte y el este.

Las fotografías aéreas existentes no proporcionan una cobertura global satisfactoria, se trata de dos vuelos parciales a una escala bastante elevada, de DETENAL y la Compañía Mexicana Aerofoto. Es importante aclarar que no existe un mapa topográfico de la región en detalle.

Gracias al reconocimiento general del área que realicé durante junio de 1980, fue posible fijar en el terreno tres de los vértices de nuestro marco geográfico.

El extremo norte limitado por el paralelo $16^{\circ} 25^{\prime}$ norte, arrancaría aproximadamente de la población de Lomatán sobre el camino Comitán-Altamirano-Ocosingo, hasta las cercanías del aserradero de Santa Martha.

Se puede considerar la terracería Comitán-Ocosingo como el marco occidental, correspondiendo casi exactamente al meridiano $92^{\circ} 04^{\prime}$ oeste, cuyo vértice con el paralelo $16^{\circ} 15^{\prime}$ norte, caería en algún lugar entre las colonias Pozo Nuevo y Cajcam, sobre el camino Comitán-Independencia; por motivos prácticos considero a la colonia Pozo Nuevo como el vértice suroccidental del marco geográfico propuesto (Fig. 1).

Falta determinar el vértice suroriental, el cual debe encontrarse en algún punto del llano de La Independencia cerca de la finca Xahac.

Los marcos sur y oriental en nuestra área de trabajo son de gran importancia debido a que esta zona conectará el reconocimiento de los valles de Las Margaritas con los trabajos en la región de Chinkultic y el valle de Comitán, que realizará el profesor Carlos Navarrete, asesor de este proyecto.

El área de estudio fue dividida en cuatro zonas naturales principales:

I) La serranía divisoria entre el río de La Soledad y el río San Joaquín, así como una pequeña porción de la margen izquierda de la cañada de La Soledad.

II) El valle de Las Margaritas propiamente dicho, comprendido entre el río San Joaquín y el río Yaxhá. 
III) Un triángulo o cuña por el oeste dentro del cual quedaría todo un sistema de montes cónicos bajos y gran cantidad de pequeños valles intermontanos, que constituyen la característica topográfica distintiva de la región de Las Margaritas.

IV) Una franja de terreno al sur que comprende la serranía divisoria entre Las Margaritas y La Independencia, así como una porción de la dilatada llanura de La Independencia en dirección a los Lagos de Montebello (Fig. 1).

Estas zonas naturales se utilizan como unidades aisladas para facilitar los recorridos de la región.

El recorrido sistemático se inició en la subárea II que comprende las cuencas de los ríos San Joaquín y Yaxhá, debido a que esta región a primera vista presenta la mayor concentración de sitios arqueológicos.

Antiguamente debió ser una zona sumamente fértil, cubierta de extensos bosques de robles y pinos; en la actualidad, se encuentra terriblemente desvastada (Lám. 3).

Hacia la porción central del valle corre el río San Joaquín que es el principal abastecimiento de agua, se debe mencionar que este precioso elemento también se obtiene de aguadas grandes de naturaleza rocosa, buenos ejemplos se pueden encontrar en las colonias Jalisco y Rafael Ramírez (Lám. 7).

El paisaje está constituido por elevadas laderas completamente desprovistas de vegetación o cubiertas de chaparrales formados por robles, colorines y ocotes aislados.

Ambos bancos del río San Joaquín constituyen una vega muy fértil para las siembras. El maíz, frijol y la caña de azúcar son los principales cultígenos que se utilizan en la zona de riego. Otros productos agrícolas importantes son el café y los árboles frutales como los naranjos (Láms. 5-6).

En esta región hay varias fincas muy antiguas como El Retiro, San Mateo, San Joaquín y el Quiz. Que actualmente conviven con colonias ejidales como Jalisco, Veracruz, La Libertad y Saltillo.

En las dos temporadas de campo se ha localizado un total de 20 zonas arqueológicas dentro de la subárea II; en cuatro de ellas se ha realizado un levantamiento topográfico, de doce se han hecho planimetrías acompañadas de una descripción detallada y solamente en cinco sitios se ha terminado la recolección de los materiales de la superficie.

Cabe mencionar que en esta región el término "cimientos" se utiliza en forma genérica para denominar zonas arqueológicas, su 
equivalente en tojolabal es $T z^{\prime}$ acabaltic y significa literalmente piedras acomodadas o muro.

Las características de los sitios arqueológicos en la región pueden agruparse en dos tipos principales:

1. Se trata de grupos de escasos montículos de tierra, asentados sobre ligeras elevaciones de la llanura aluvial de la margen izquierda del río San Joaquín (Lám. 8).

No se aprecian piedras de construcción, aunque en los asentamientos mayores hay fragmentos de losas grandes que pudieron servir como monumentos (altares o estelas). Se debe mencionar que la presencia de cerámica es casi nula, factor que dificulta e su fechamiento (Lám. 10).

De los siete sitios localizados con estas características, solamente tres son agrupaciones de más de ocho montículos, todos los demás consisten de uno o dos montículos aislados de poca altura (Láms. 11-12).

Excavaciones realizadas por la Fundación Arqueológica del Nuevo Mundo en sitios con características semejantes, del Municipio de Trinitaria han revelado que pertenecen al período Preclásico, como ejemplo se puede mencionar especialmente el sitio de la finca Santa Martha al pie del cerro de Tenam Rosario, que excavó Pierre Agriniere en 1979.

2. El segundo tipo está formado por asentamientos sobre las extensas laderas de los arrugados macizos montañosos que caracterizan a la región (Lám. 9).

Los sitios consisten básicamente de terrazas que nivelan la parte alta de los cerros, para sustentar pequeños basamentos, construidos ambos con bloques finamente labrados (Láms. 16-17-18).

Este sistema de terrazas con un pequeño grupo ceremonial en la parte superior, se puede encontrar circundando a un cerro cónico aislado, como en el Shintagual o cubriendo hasta ocho cerros como en el Najlem o la Libertad (Lám. 4).

En la mayoría de los casos, los muros de las terrazas que sustentan a los grupos principales, presentan fragmentos bien conservados, hasta de 40 metros de largo, con alturas variables entre 1 y 3 metros (Láms. 19-20).

Las estructuras principales sobre la terraza de la parte superior son pequeños basamentos de bloques labrados, pudiéndose apreciar considerables tramos de los muros originales; los que también se encuentran en las terrazas inmediatamente inferiores (Láms. 1314-15). 
Estos pequeños edificios son considerados principales debido a su ubicación predominante en el terreno, mas que por sus dimensiones (Láms. 26-27).

Es importante mencionar la presencia de tumbas de forma rectangular o elíptica construidas de piedras bien labradas y con grandes losas muy delgadas como tapas; así como abundantes chultunes, en los cuales he encontrado evidencias de que fueron utilizados para enterramientos en alguna época.

Me fue posible fotografiar dos vasijas: una tinaja y un cajete trípode con soportes cilíndricos provenientes de saqueos en estos chultunes, de los sitios Najlem y los cimientos de la Libertad (Láms. 35-36).

En base a las descripciones de los parientes de los saqueadores se puede inferir que fueron utilizadas como urnas funerarias.

En la parte superior de los cerros es común encontrar una plataforma aislada de forma rectangular que sustenta a dos pequeñas estructuras funerarias.

Los saqueos realizados en una de estas estructuras del sitio Shintagual muestran los fragmentos de las fosas de dos tumbas hechas con piedras bien labradas (Fig. 2).

También es frecuente encontrar, en la pequeña plaza o espacio abierto al frente del basamento principal, montículos de poca altura con el mismo sistema constructivo, así como los restos de las fosas de tumbas saqueadas (Lám. 34).

La semejanza de este tipo de estructuras con el grupo del mirador en Chinkultic es notoria; el edificio mayor es un basamento escalonado que sustenta a un pequeño templo, que tiene una cámara secreta en su interior.

$\mathrm{Al}$ frente tiene cuatro basamentos miniatura que se utilizaron como tumbas de personajes importantes; y cerca de la escalinata se erigió una estela grabada, durante la primera época constructiva que corresponde al período Clásico Tardío (Gallegos; 1976) (Navarrete; 1976).

Es importante mencionar que dos de estos sitios, tienen juegos de pelota cerrados de 16 y 21 metros de largo (Fig. 3).

En el mayor y mejor conservado, que se encuentra en el sitio Najlem de la colonia Veracruz, se pueden apreciar tramos bastante largos (de $10 \mathrm{~m}$. a $18 \mathrm{~m}$. de los muros originales de sillares labrados de distintas dimensiones). También se conservan casi completos los muros en talud de ambos cuerpos, así como los grandes bloques de las banquetas (Láms. 21-22). 
En el extremo sur se distinguen restos de la escalinata de acceso a la parte superior y arriba de este cuerpo, así como sobre algunas de las estructuras que limitan el cabezal oeste se observan grandes bloques cuadrangulares que posiblemente funcionaron como tapas de tumbas (Láms. 23-24-25).

Asimismo, el cabezal oeste es mayor que el cabezal este, característica similar al juego de pelota de Chinkultic.

Un posible tercer juego de pelota se encuentra en el sitio de Los Cimientos de la Libertad, aunque su forma no ha sido claramente determinada; asociadas a los cuerpos hay dos esculturas grandes labradas en forma de cabezas de felino que son denominadas localmente como los "Leones de la Libertad".

Una orientación de $50^{\circ}$ suroeste en la cancha es constante en las tres estructuras.

En esta zona arqueológica se han localizado varias estelas lisas de 3 a 5 metros de largo, asociadas a altares cuadrangulares o cilíndricos presentándose al frente de estructuras ceremoniales.

Una variante interesante de este tipo de sitios arqueológicos, la forman extensas terrazas hechas de piedras bien labradas; que presentan forma y distribución irregular, y aprovechan afloramientos naturales, conformándose a las laderas de los cerros (Láms 29-30).

Estas terrazas cuando se encuentran próximas a los grupos de la cumbre pueden ser hasta de 3 metros de alto con montículos habitacionales de poca altura y abundantes materiales arqueológicos. Generalmente las terrazas descienden hasta la parte inferior de los macizos montañosos, donde no se encuentran ni montículos, ni cerámica sobre ellas; éstas no rebasan el uno y medio mts. de altura y se extienden por varios kilómetros en distintas direcciones, adaptándose a las laderas rocosas, alcanzando a unir sitios o grupos de estructuras separados 6 kilómetros (Láms. 31-32-33).

Sería de gran interés realizar excavaciones en algunos de los pequeños montículos habitacionales, con la finalidad de conocer las características de las casas, así como hacer pozos estratigráficos en las terrazas inferiores para obtener muestras de polen que permitan determinar si fueron utilizadas para cultivo.

Se pueden considerar como factores que aumentan la dificultad del reconocimiento de las terrazas: la distribución irregular de éstas sobre las laderas y el hecho de que la Secretaría de la Reforma Agraria otorgó parcelas orientadas transversalmente a la dirección de las terrazas. Los ejidatarios quitan las piedras labradas para hacer los tecorrales de sus propiedades y esto ocasiona que las terrazas 
se erosionen rápidamente por la lluvia, el viento y otros factores, quedando solamente la silueta de dichas terrazas.

Entre los abundantes materiales arqueológicos encontrados en las terrazas próximas a las estructuras principales se pueden mencionar: una cerámica gruesa con engobe color rojo muy pulido, que a veces presenta decoración de motivos geométricos en formas de incensarios; también son frecuentes dos tipos de cerámica doméstica delgada de colores café y anaranjado con desgrasante de calcita o bax, bastante grueso, así como incensarios de barro grueso color café con decoración de perforaciones o al pastillaje que a veces presenta engobe blanco, y por último una cerámica negra o café muy oscuro, más escasa. También se deben agregar dos fragmentos de figurillas antropomorfas de barro café.

Como materiales líticos se pueden mencionar principalmente varios fragmentos de hachas y cinceles pequeños de piedras verdes duras similares a los que se encuentran en Chichicastenango, también hay escasas lascas y fragmentos pequeños de navajas de obsidiana color gris veteada muy transparente así como algunos núcleos y lascas de silex y pedernal.

Es importante mencionar la presencia en casi todas las zonas arqueológicas de abundantes fragmentos de metates y morteros de granito rojizo, así como cantos de río que sirvieron como pulidores de cerámica y una piedra semejante a la escoria de un horno de color ocre ferroso; es posible que de esta piedra se obtuviera el colorante rojizo para la cerámica.

El tipo rojo pulido en los muestrarios de la Fundación del Nuevo Mundo aparece desde el período Clásico Temprano y los incensarios de barro café con decoración de pastillaje o perforaciones se encuentra en el Postclásico (comunicación personal, Bryant y Agriniere).

Es indudable que el análisis de la cerámica, permitirá establecer una cronología inicial bastante precisa, para la región de Las Margaritas.

La mayoría de las inscripciones en los sitios importantes de regiones cercanas a Las Margaritas, como Toniná, Chinkultic, Santa Elena Poco Uinic, Sachaná y Tenam Puente, presentan fechas del Clásico Tardío (600-900) y del inicio del Postclásico (900-1200).

En total son más de 20 inscripciones que pueden hablar de un incremento demográfico notable durante el final del período Clásico y el inicio del Postclásico (Blom; 1925) (Palacios; 1928) (Gallegos; 1976). 
A primera vista los datos presentados anteriormente, muestran una intensa ocupación humana en nuestra área de estudio, cuyos inicios arrancan desde el periodo Preclásico continuándose prácticamente hasta nuestros días.

Resultará de gran interés intentar una reconstrucción imaginaria de la historia cultural de la región, buscando las diferentes formas de interacción entre el hombre y su medio ambiente. Es evidente que ha existido a través de los siglos una intensa utilización del ecosistema por parte de sus moradores y las fuerzas que han interactuado, no parecen fáciles de interpretar.

Es posible suponer que el esclarecimiento de ciertos aspectos oscuros acerca de la arqueología en esta zona, permitirán establecer puntos de comparación a través de analogías etnográficas entre los pobladores actuales y el patrón de asentamiento prehispánico.

\section{Trabajos arqueológicos anteriores en la región de Las Margaritas}

Existen en los volúmenes VI y VII de los documentos inéditos, concernientes al Estado de Chiapas, del Archivo Técnico del Instituto Nacional de Antropología e Historia, riquísimos materiales en los reportes de algunos viajeros y arqueólogos aficionados; estas breves descripciones de los sitios son especialmente importantes debido a que algunas se remontan hasta hace medio siglo, reportando evidencias que han desaparecido en la actualidad, aunque la mayoría de los sitios todavía existen en avanzado grado de destrucción.

Se deben considerar en primer término los reportes de don Mauro Quintero, arqueólogo aficionado local y encargado de los monumentos prehispánicos durante los años 30 s.

También es importante hacer mención a un breve reconocimiento, por nuestra área de estudio, que realizó el reverendo J. Coffin durante febrero de 1937.

Fueron muy abundantes y frecuentes los reportes de don Mauro Quintero a la dirección del Instituto de Antropología, en ellos hay innumerables menciones a varias de las zonas arqueológicas que yo he encontrado, así como menciona infinidad de otros sitios en la región; especialmente recopiló dos listas, una de ellas acompañada de un mapa, en las que a petición del Arq. Marquina, consignó los sitios existentes en cada finca de la región a su cargo, con algunas anotaciones de su importancia y facilidades de acceso (Archivo I.N.A.H., vol. VII; F: 48/72).

Varios de los sitios mencionados en los reportes antiguos se encuen- 
tran fuera del área de estudio propuesta, sin embargo, estas descripciones serán de gran importancia para la realización de las próximas temporadas de campo, así como para la elaboración del Atlas Arqueológico de la región, especialmente las dos listas mencionadas.

Don Mauro Quintero fue un celoso guardián de las zonas arqueológicas bajo su custodia, en contra de los buscadores de tesoros y las invasiones de los agraristas; como ejemplos se pueden mencionar los sitios de Comanajab en la finca Las Cruces y el de Los Cimientos de Las Margaritas (Archivo I.N.A.H., vol. VII; F: 19).

Es importante aclarar que los cinco sitios que Coffin denomina como: Los Cimientos, Canhuitz, El Coyol, Palma Real y El Sapo, deben corresponder al sitio que yo designé como Los Cimientos de Las Margaritas; en mi informe solamente describí los dos grupos de estructuras principales, pero existen en las cercanías otros cerros semejantes que parecen sustentar montículos; es posible que a este sitio Quintero lo llame la zona arqueológica en la ciénega de Las Margaritas; en su reporte de febrero 22 de 1934, presenta la fotografía de un muro de estuco en excelente estado de conservación, en la parte exterior de un pequeño basamento funerario; este sepulcro Coffin lo reporta totalmente saqueado y yo solamente encontré fragmentos de dicho muro de estuco (Archivo I.N.A.H., vol. VI; F: 19/20).

Existen grandes diferencias en la ortografía de las toponimias de los sitios arqueológicos, en los reportes antiguos y las que he registrado en la actualidad.

El sitio que se describe como Chisintagual, es sin duda el que yo designo como Shintagual, así como el sitio que Quintero denomina Cerro Manglem debe corresponder al sitio que yo reporto como Najlem de la colonia Saltillo (Archivo I.N.A.H., vol. VI; F: 20/30/37/38).

Por último se debe agregar que los objetos que publica Blom (1925: 418) según información de Quintero, se encontraron en un montículo que fue destruido al construir una calle en el pueblo de Margaritas y que se encontraba en las cercanías del sitio de Los Cimientos, se trata de un vaso plumbate y una vasija en forma de caracol (Archivo I.N.A.H., vol. VI; F: 19). 


\section{BIBLIOGRAFIA}

Archivo Técnico del Instituto Nacional de Antropología e Historia, Volúmenes No. VI y VII, de los documentos inéditos relativos al Estado de Chiapas.

Blom, F., La Farge, O.

1925 Tribes and Temples.

Tulane University, New Orleans.

Gallegos, R.

1976 Chikultic: una ciudad maya y su culto a la lluvia. Editorial Texto e Imagen, S. A. México, D. F.

Helbig, C.

1976 Geografía de Chiapas. Ediciones del Gobierno del Estado. Tux.

Miranda, F. tla Gutiérrez, Chiapas.

1952 La vegetación de Chiapas. Ediciones del Grobierno del Estado. Sección autográfica. Departamento de Prensa y Turismo. Tuxtla Gutiérrez, Chiapas.

MUllerted, F.

1959 Geología de Chiapas. Academia Nacional de Giencias. T. 58 Núm. 3-4 México, D. F.

NAvarrete, C.

1976 "Chinkultic (Chiapas). Trabajos realizados en 1976". en Boletín I.N.A.H. época II. octubre-diciembre. Instituto Nacional

Orellana, R. de Antropología e Historia. México, D. F.

1978 Relaciones clima vegetación en la región lacandona, Chiapas. T'esis profesional para obtener el título de biólogo de la Facultad de Ciencias de la UNAM, inédita

Palacios, E. J.

1926 En los confines de la selva lacandona; exploraciones en el Estado de Chiapas: mayo-agosto de 1926. Contribución de México al XXIII Congreso de Americanistas. Talleres Gráficos de la Nación. México, D. F. 


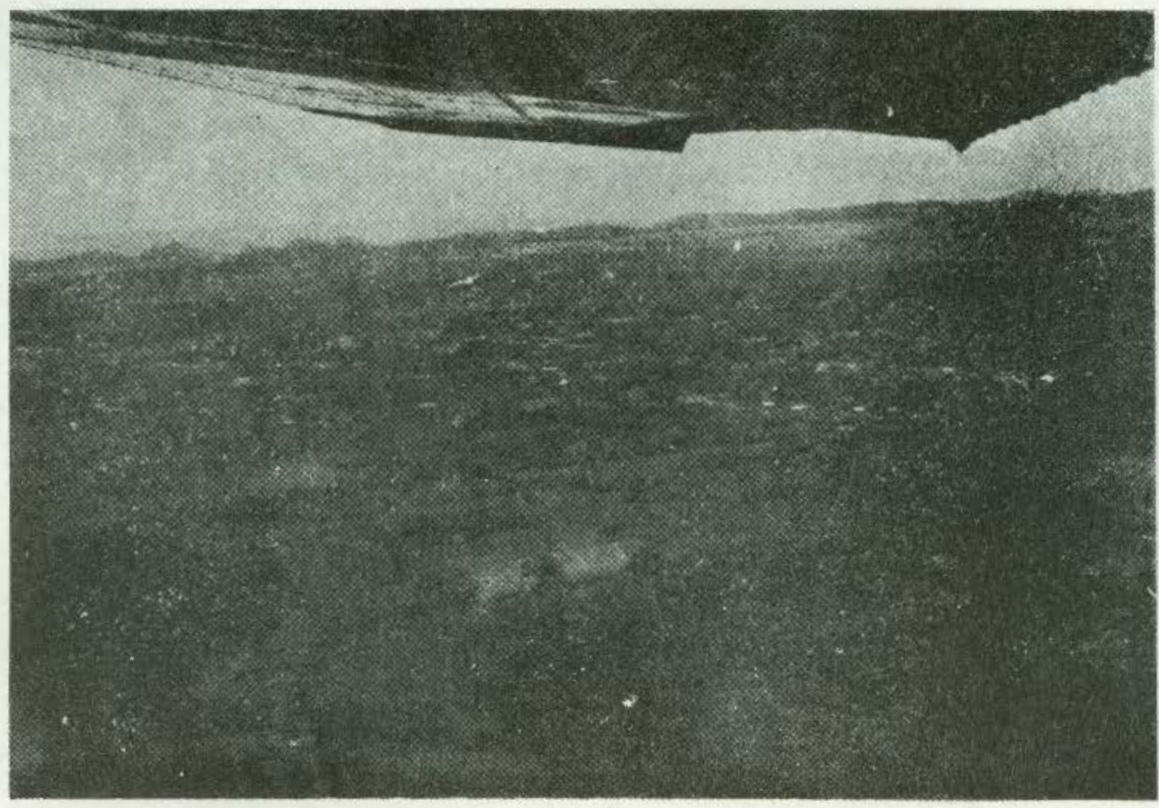

Lámina 1. Vista aérea de Las Margaritas.

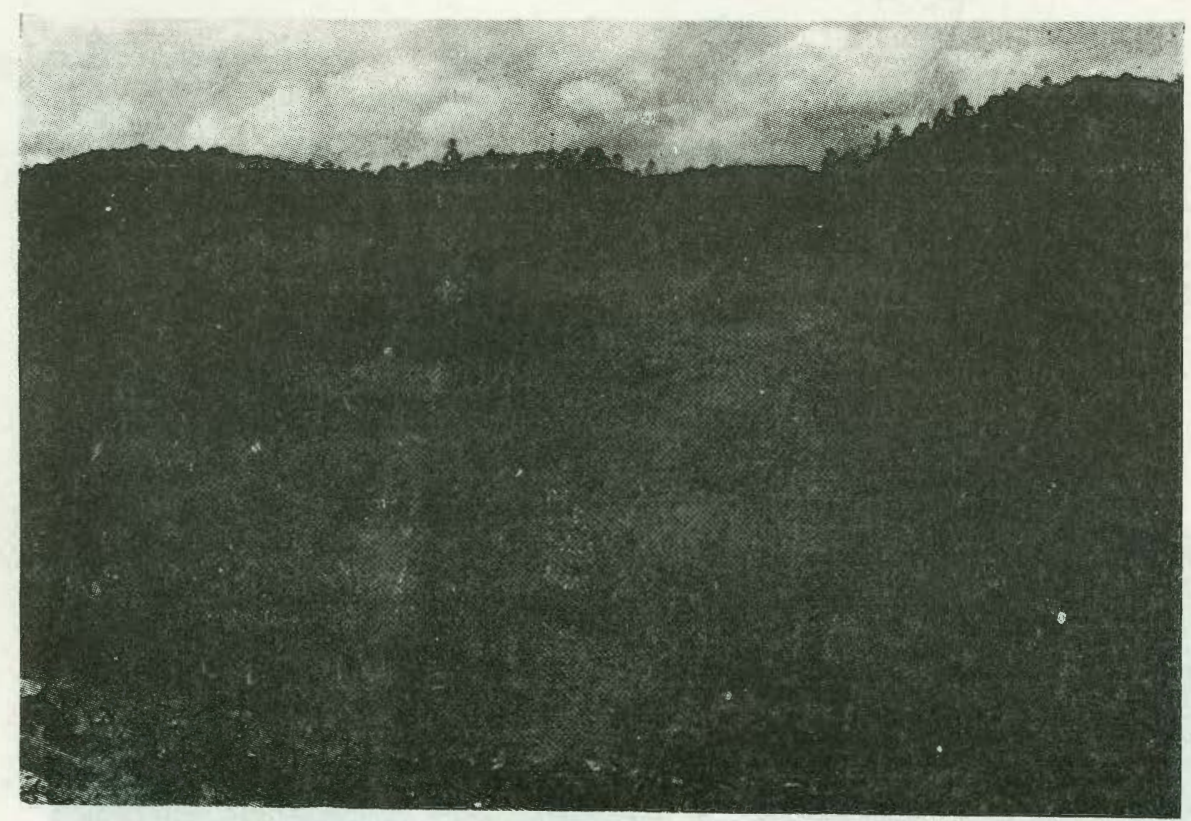

Lámina 2. Bosque mixto de pinos y robles.

Estudios de Cultura Maya. Vol. XIV, 1982

Instituto de Investigaciones Filológicas/

Centro de Estudios Mayas, UNAM

http://www.iifilologicas.unam.mx/estculmaya/ 


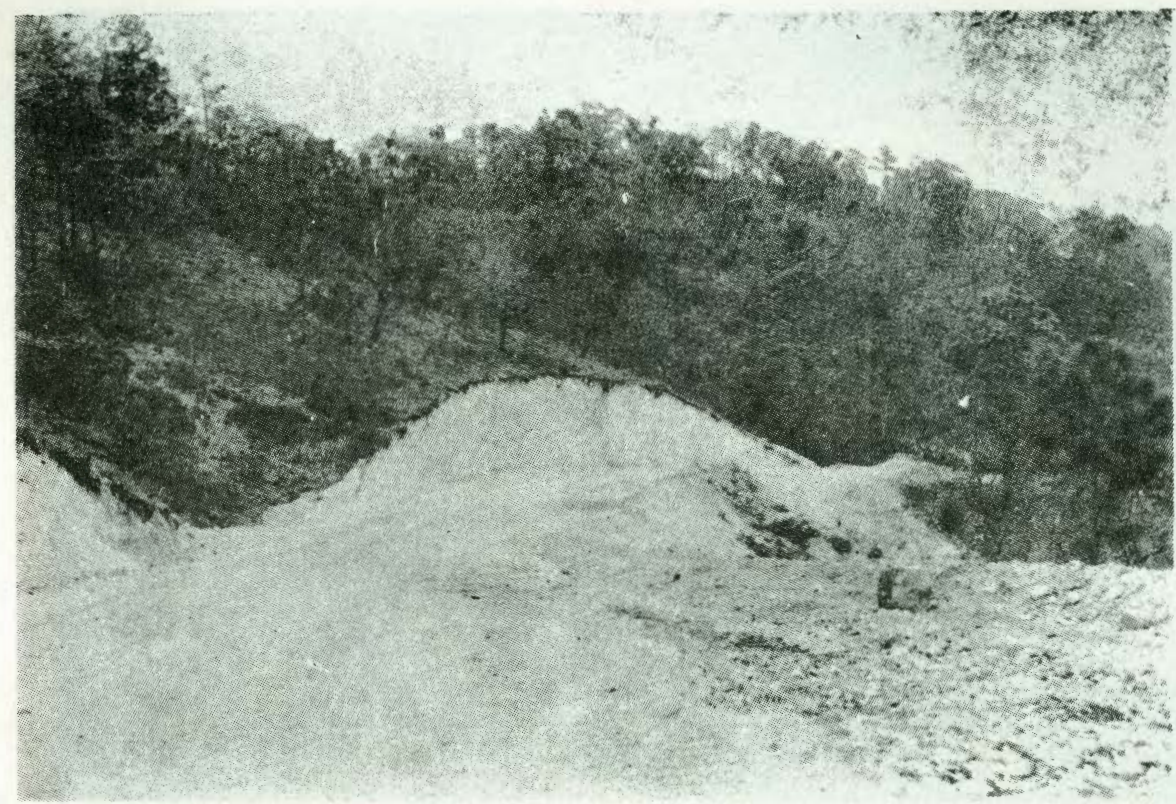

Lámina 3. Bosque de robles. En el corte del camino se puede apreciar la capa humítica de $30 \mathrm{~cm}$. de espesor.

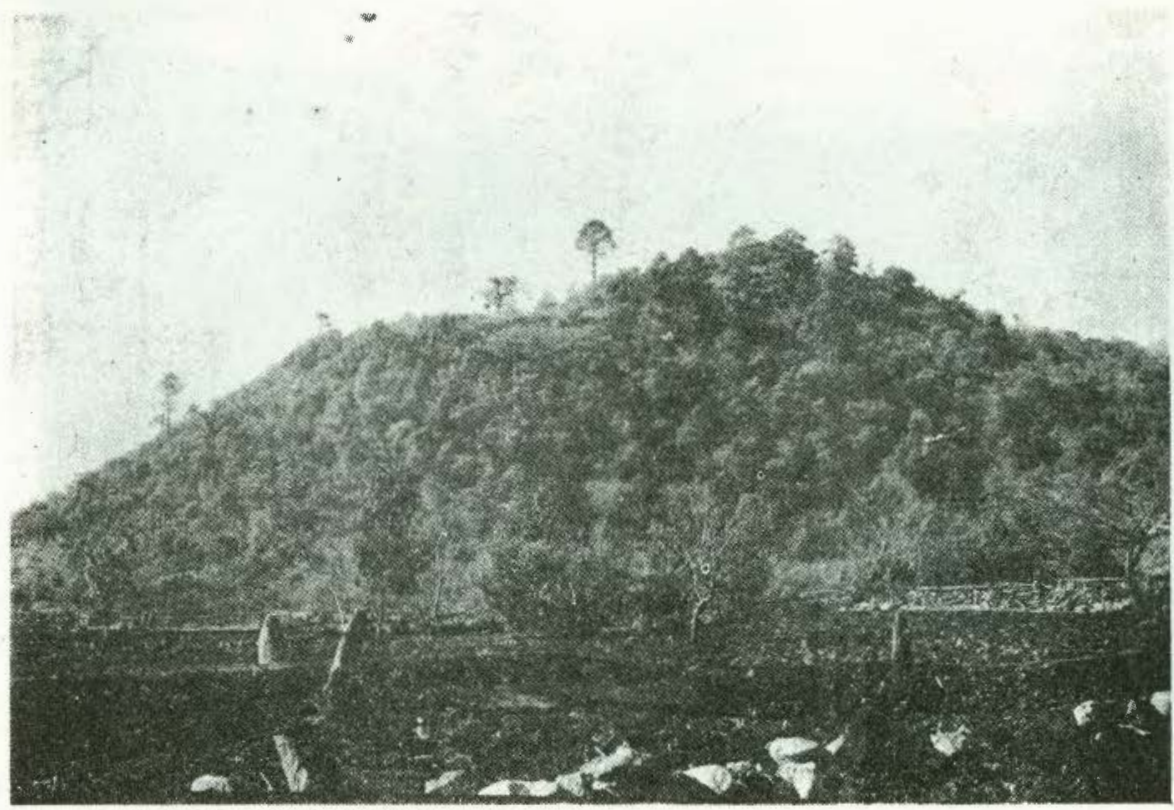

Lámina 4. Cerro Najlem en la colonia Veracruz. 


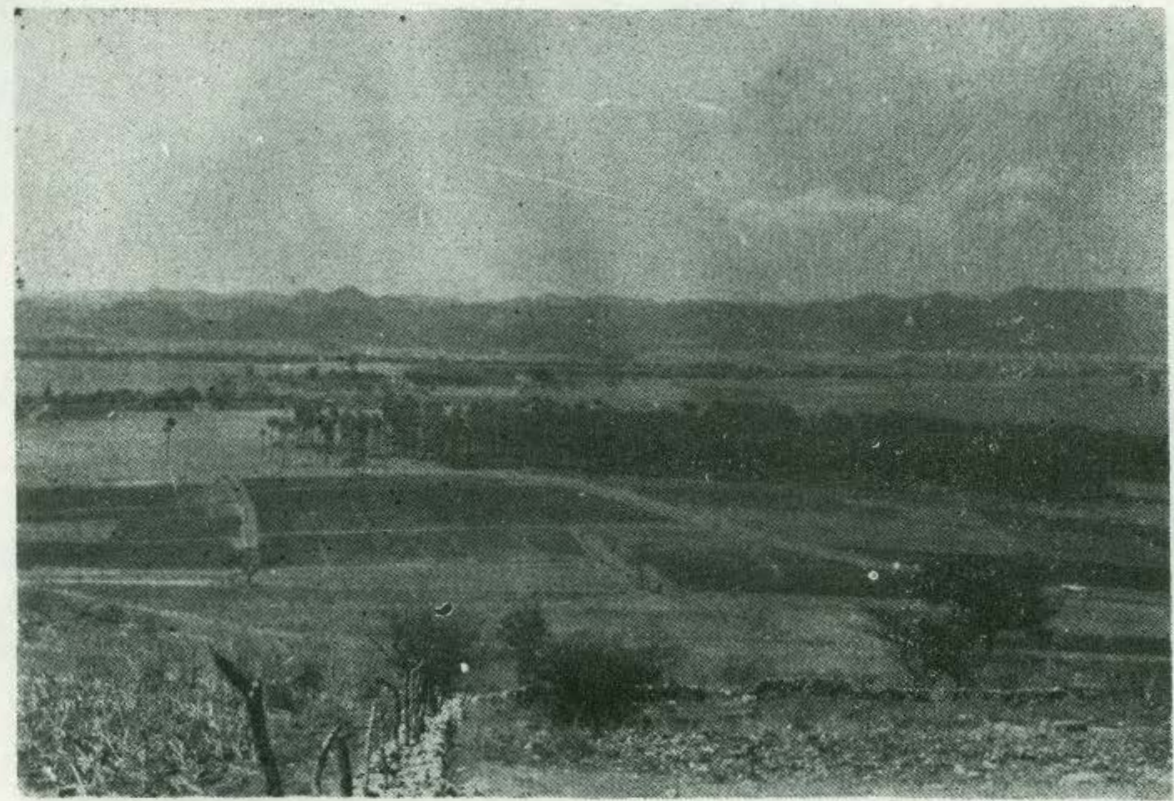

Lámina 5. Vista parcial de la cuenca del río San Joaquín.

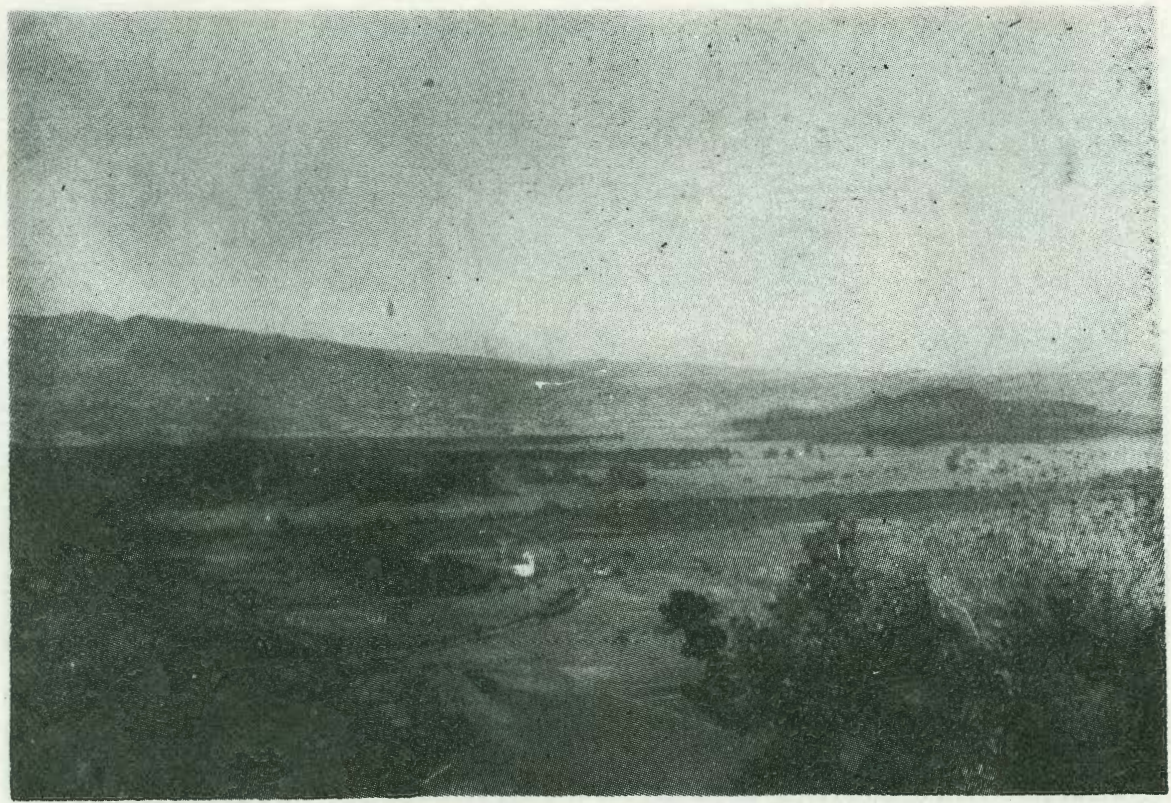

Lámina 6. Extremo-Oeste de la cuenca del río San Joaquín.

Estudios de Cultura Maya. Vol. XIV, 1982

Instituto de Investigaciones Filológicas/

Centro de Estudios Mayas, UNAM

http://www.iifilologicas.unam.mx/estculmaya/ 


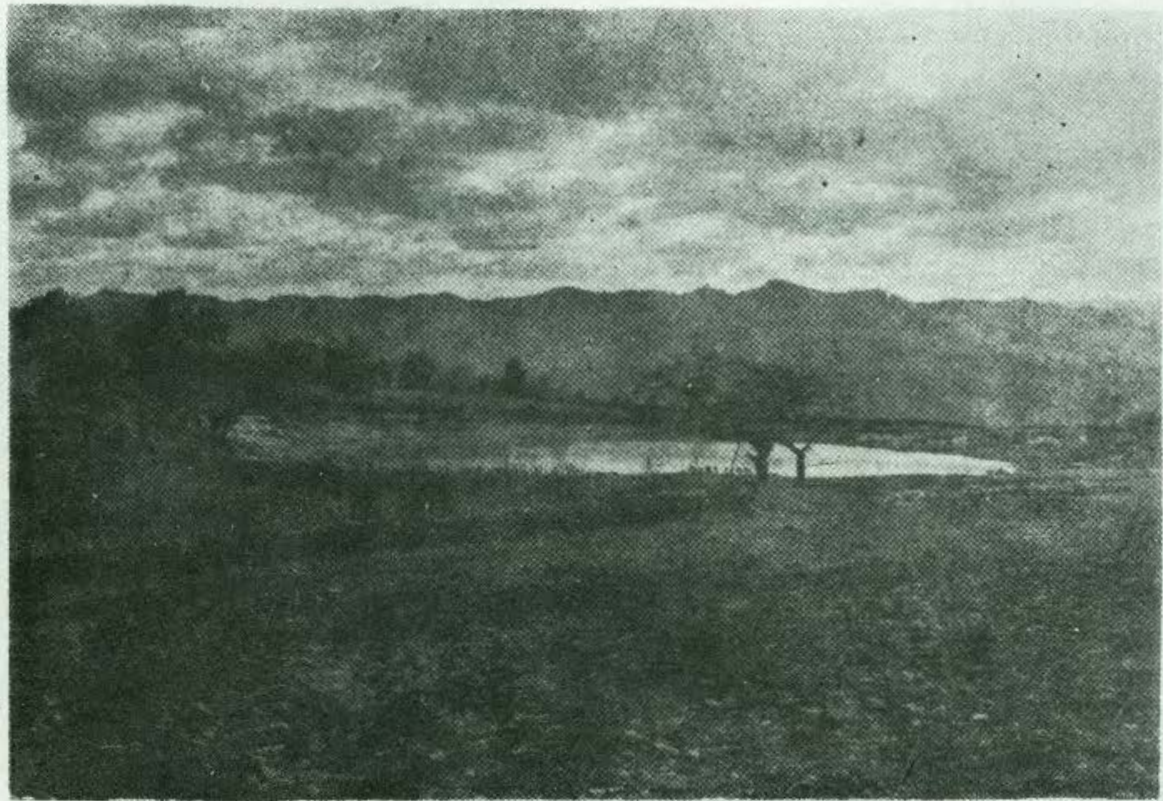

Lámina 7. Aguada de la colonia Jalisco.

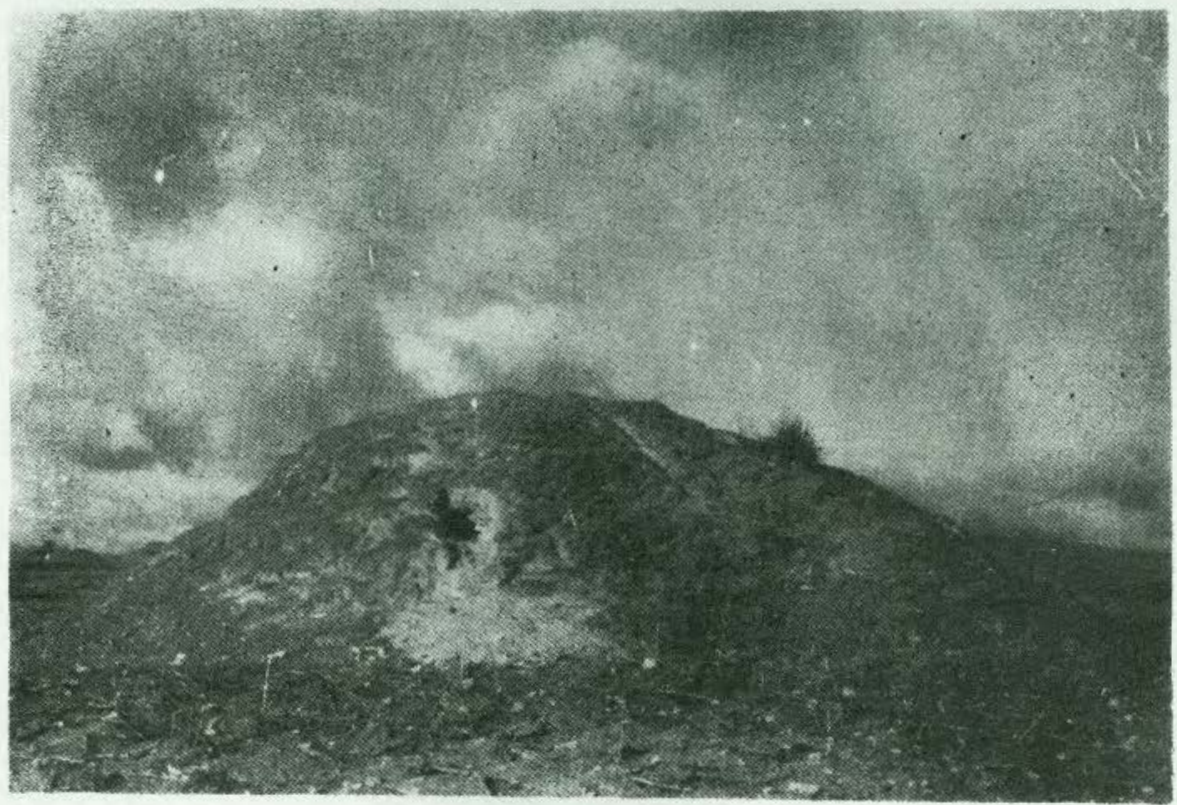

Lámina 8. Montículo principal en el sitio MAR-II-3.

Estudios de Cultura Maya. Vol. XIV, 1982

Instituto de Investigaciones Filológicas/

Centro de Estudios Mayas, UNAM 


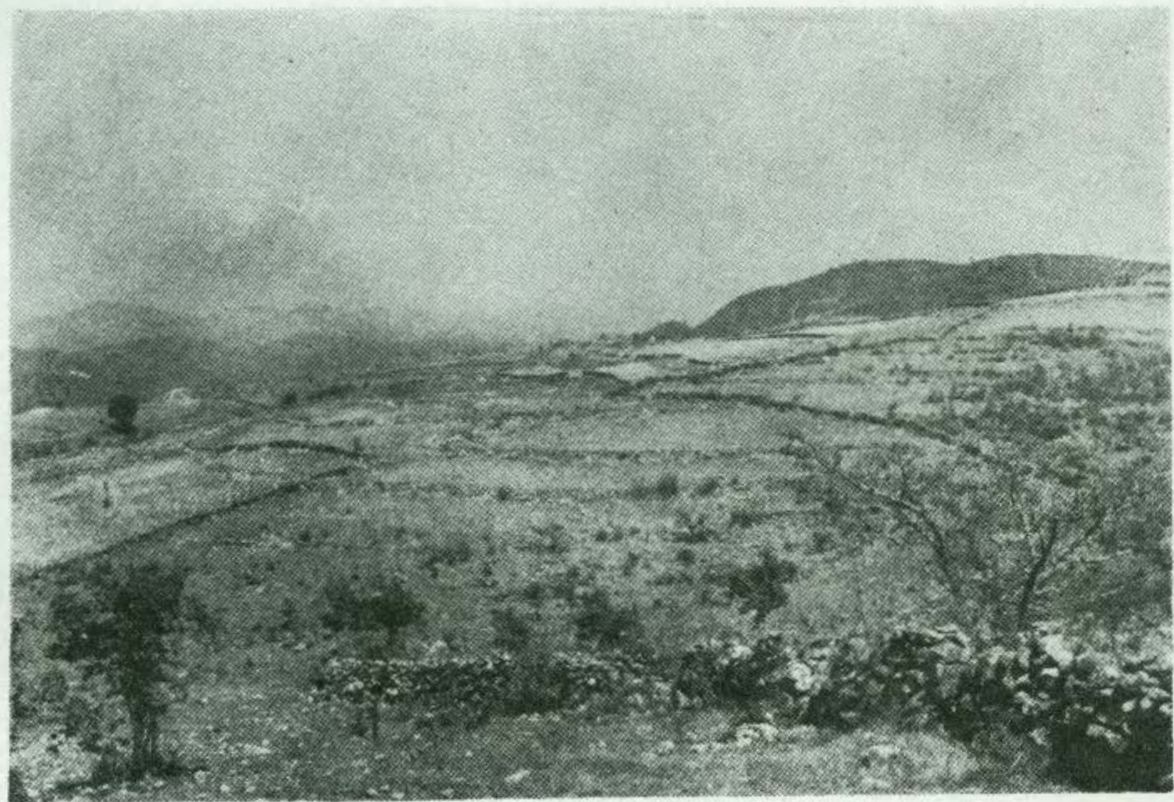

Lámina 9. Vista de las terrazas abajo del sitio MAR-II-3.

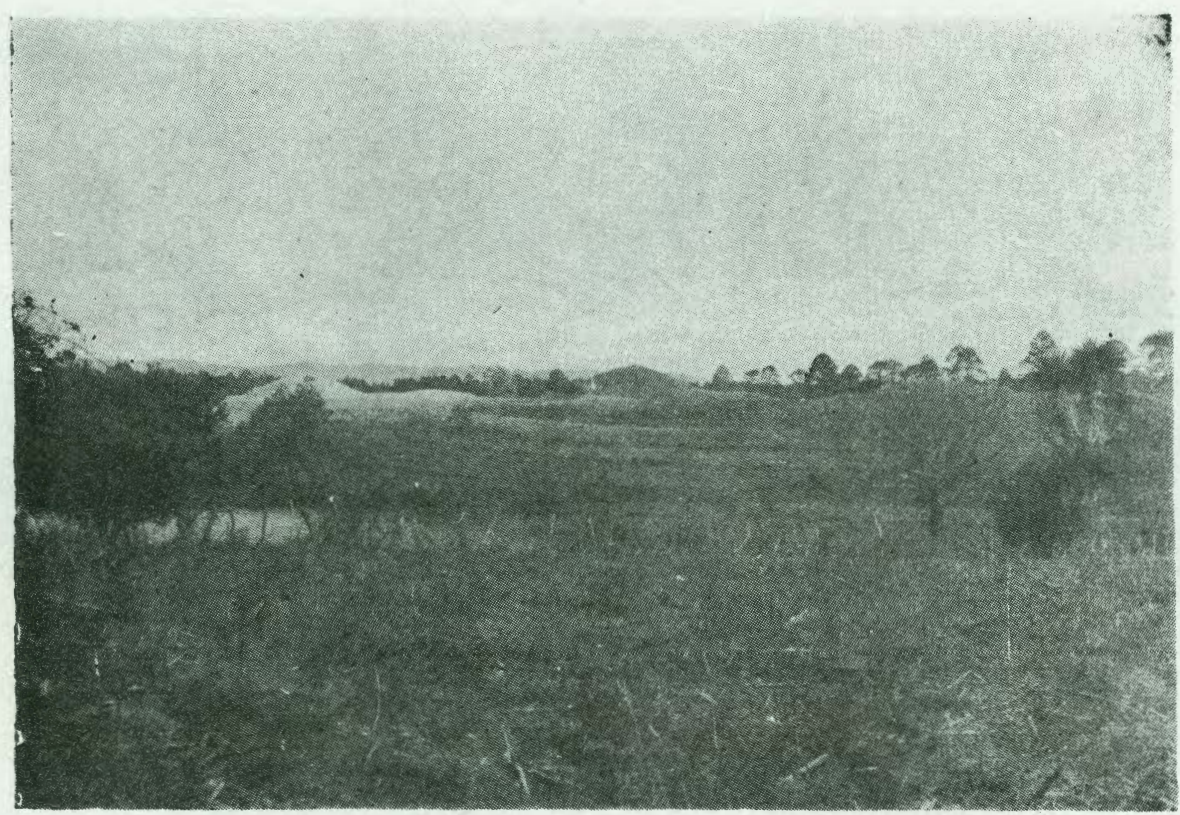

Lámina 10. Vista parcial del sitio MAR-II-9, cerca de la finca El Quiz. 


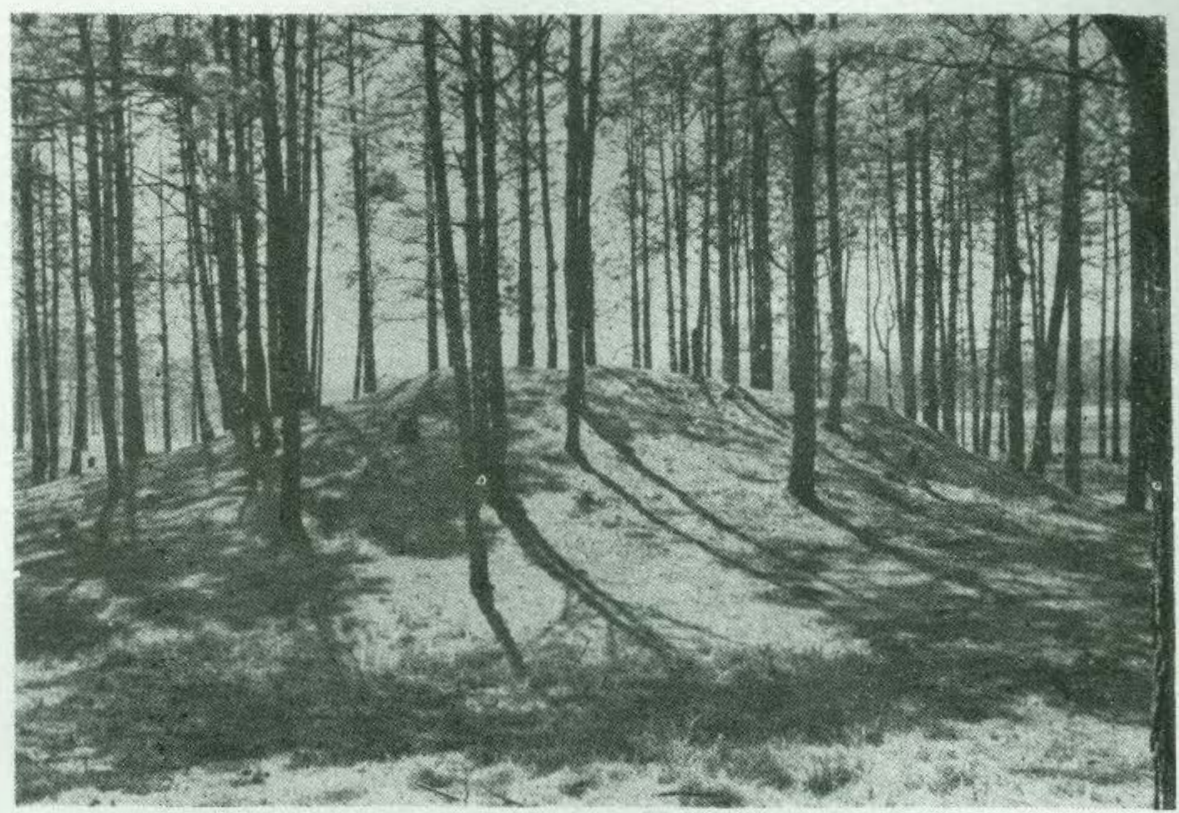

Lámina 11. Vista de los montículos en el sitio MAR-II-5.

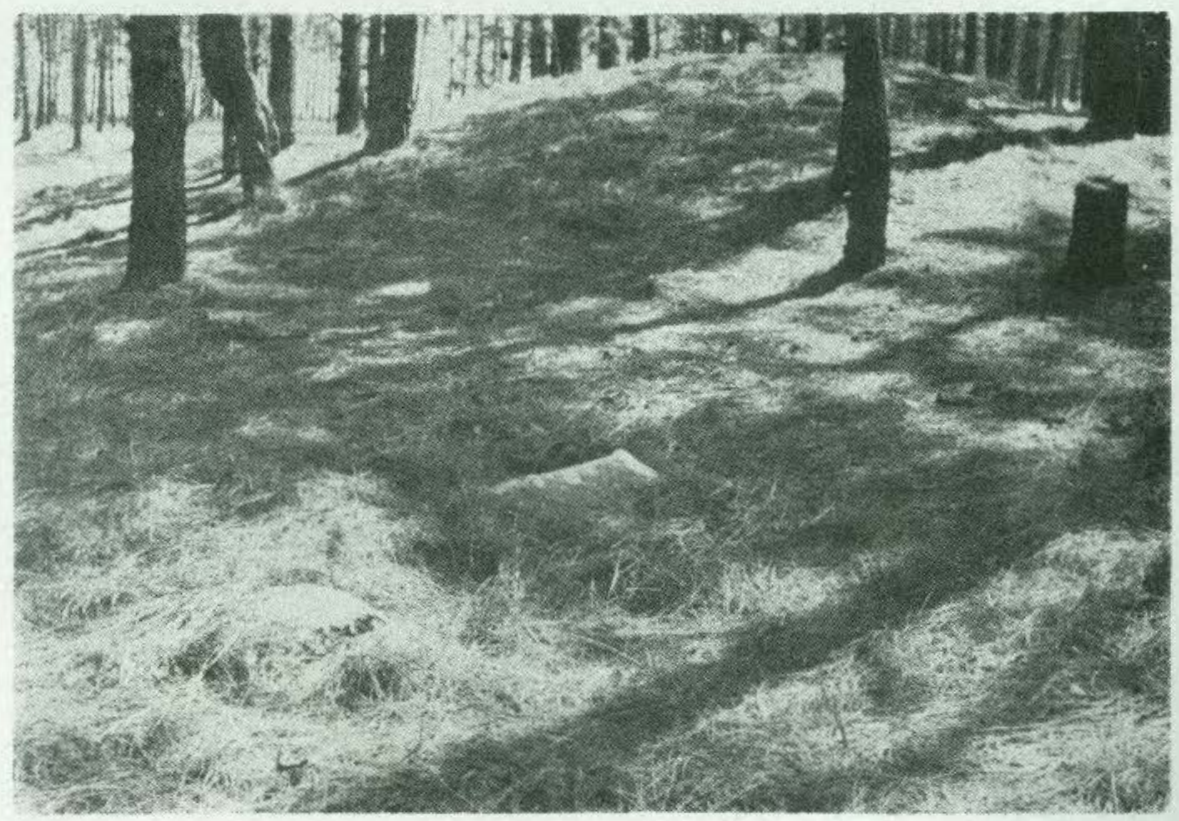

Lámina 12. Vista de los montículos en el sitio MAR-II-5. 


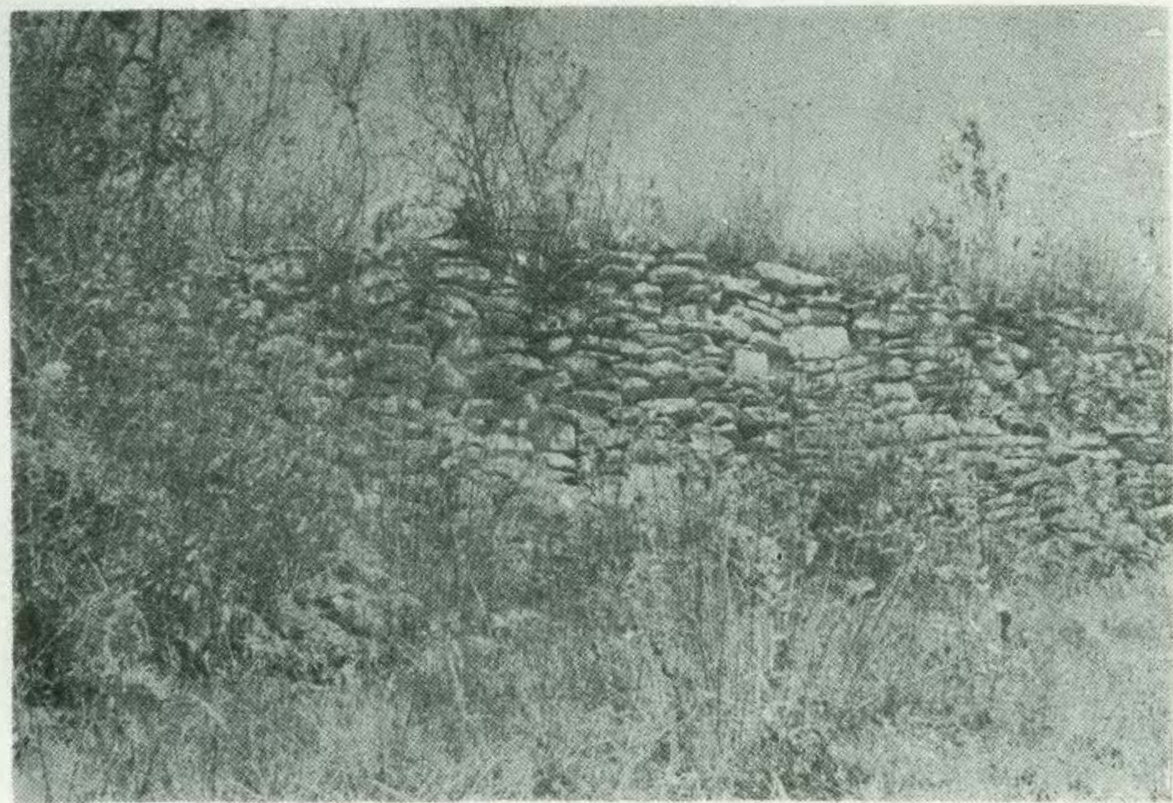

Lámina 13. Vista de los muros de las terrazas en el grupo principal del sitio MAR-II-4.

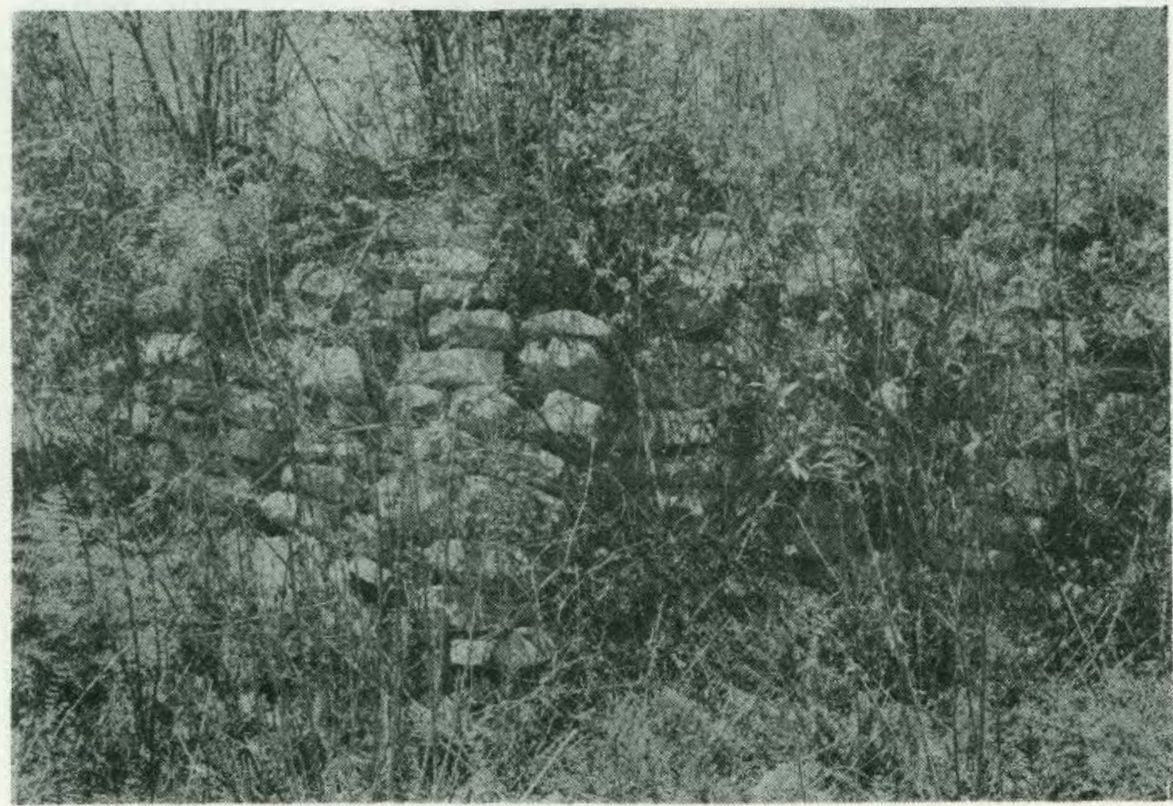

Lámina 14. Vista de los muros de las terrazas en el grupo principal del sitio MAR-II-4. 


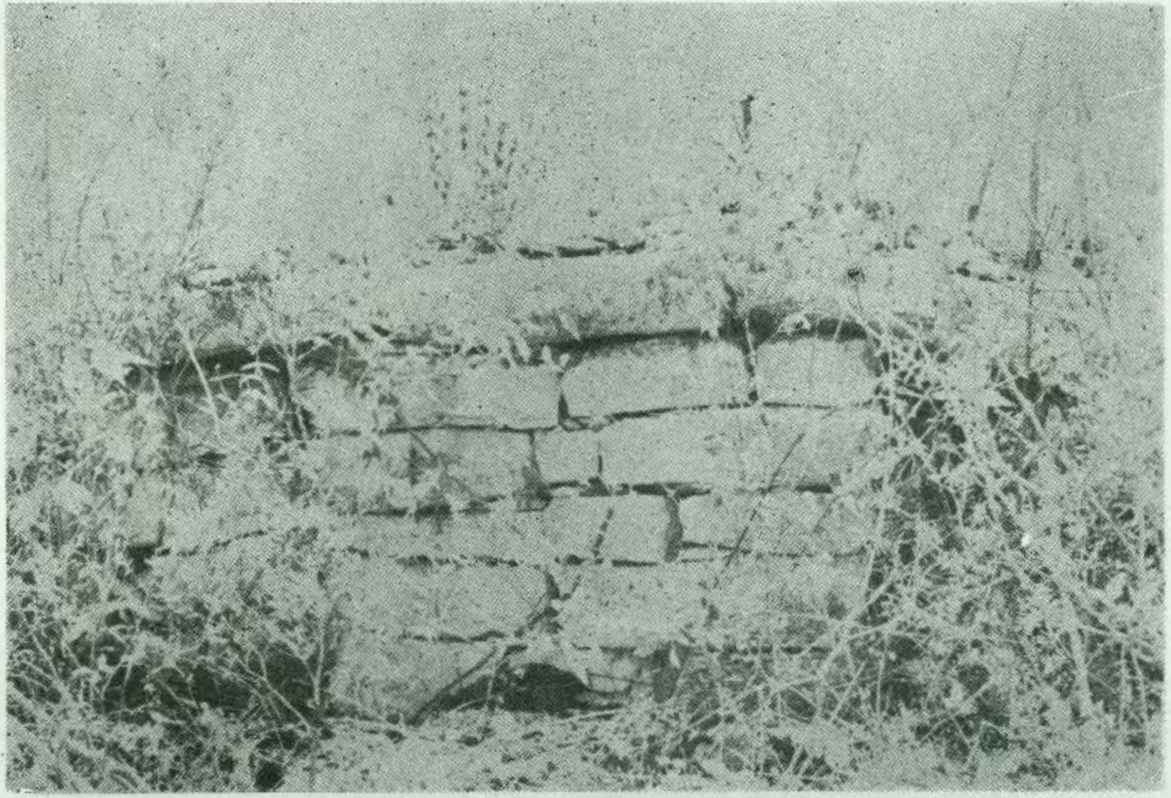

Lámina 15. Restos del muro original y la cornisa de un pequeño basamento funerario en el sitio MAR-II-4.

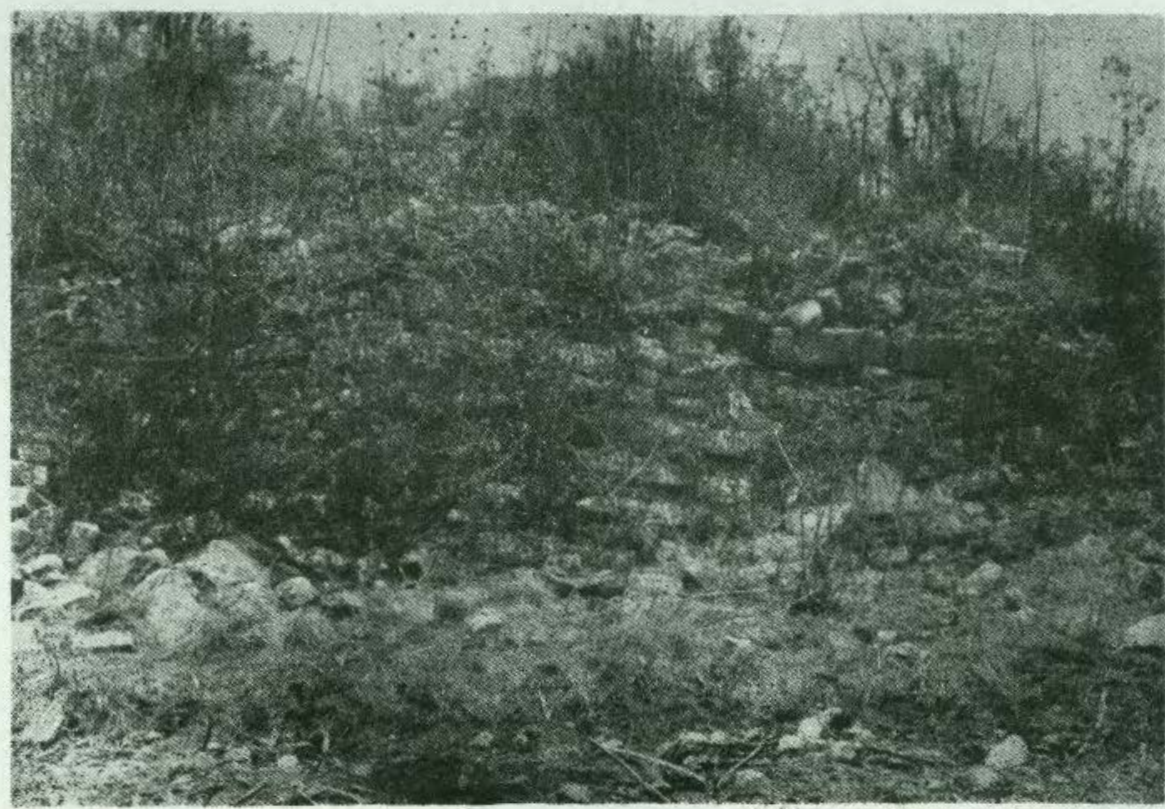

Lámina 16. Vista de los muros de las terrazas que sustentan estructuras habitacionales en el sitio Najlem MAR-II-1. 


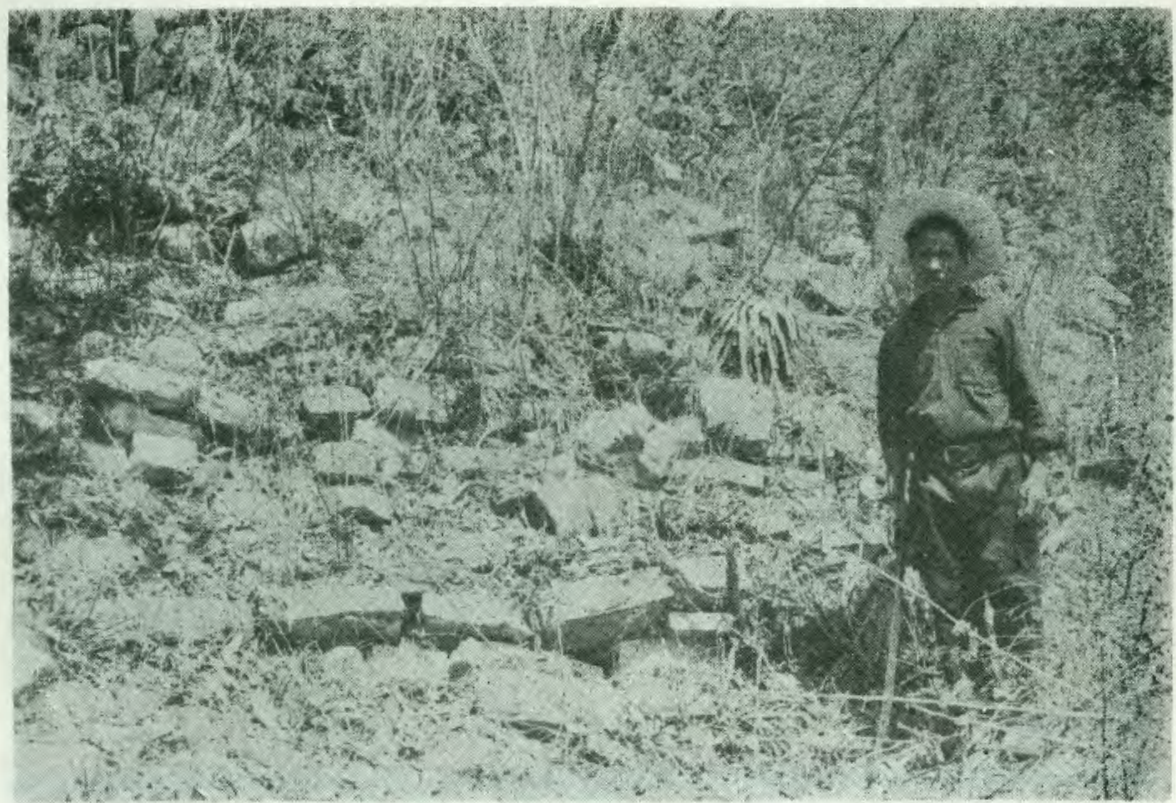

\section{Lámina 17.}

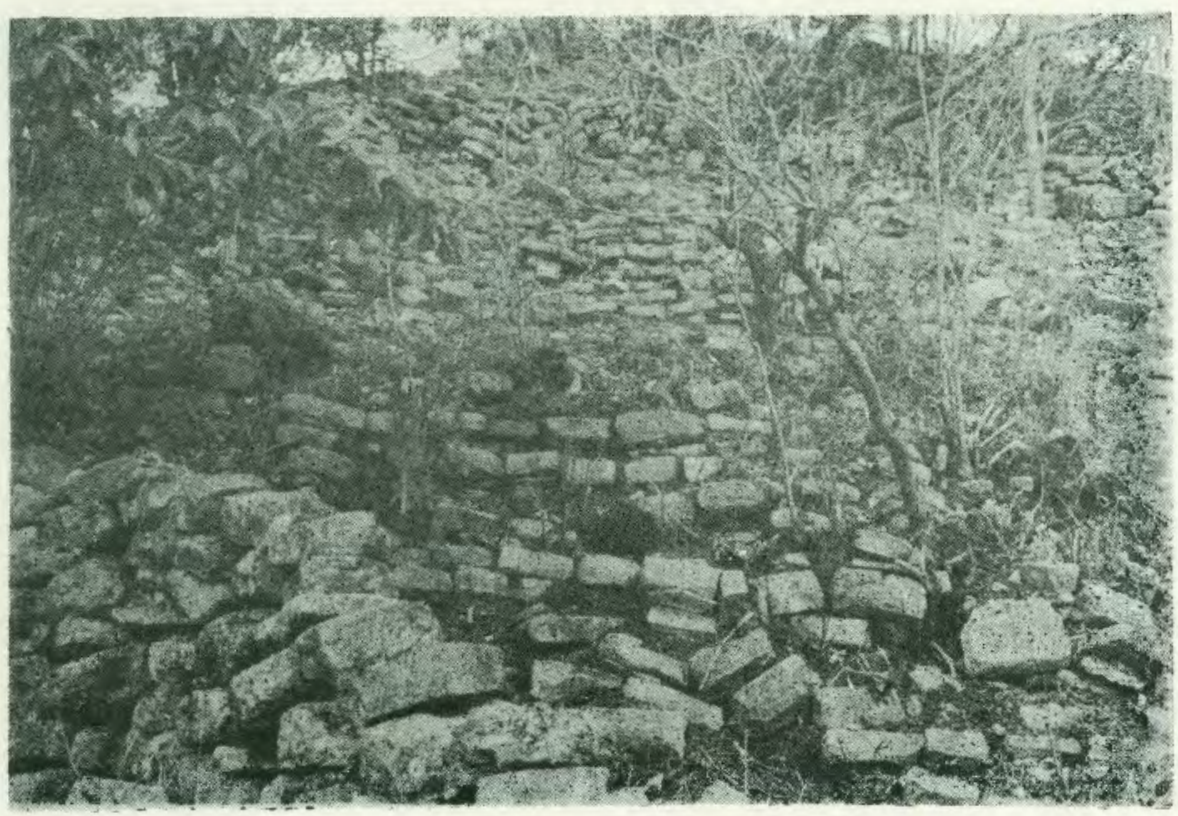

Lámina 18.

Estudios de Cultura Maya. Vol. XIV, 1982

Instituto de Investigaciones Filológicas/

Centro de Estudios Mayas, UNAM

http://www.iifilologicas.unam.mx/estculmaya/ 


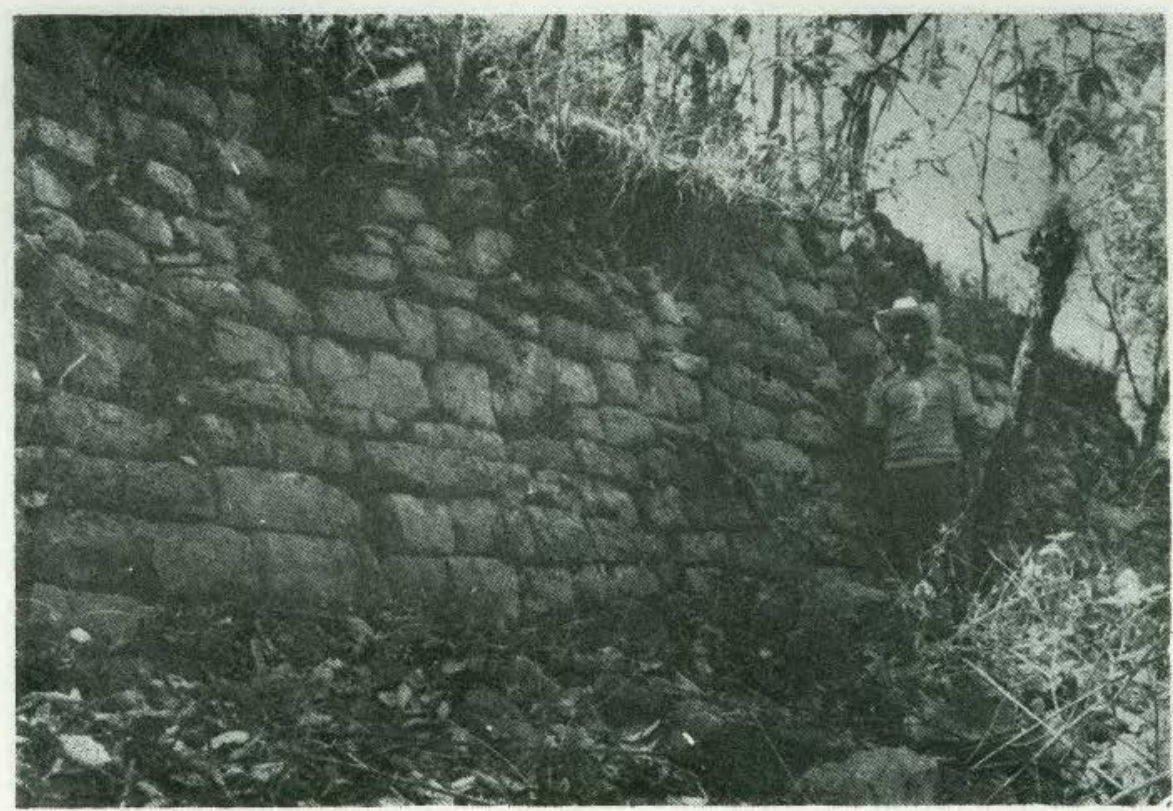

Lámina 19. Vistas del muro original de la terraza del grupo principal en MAR II-1.

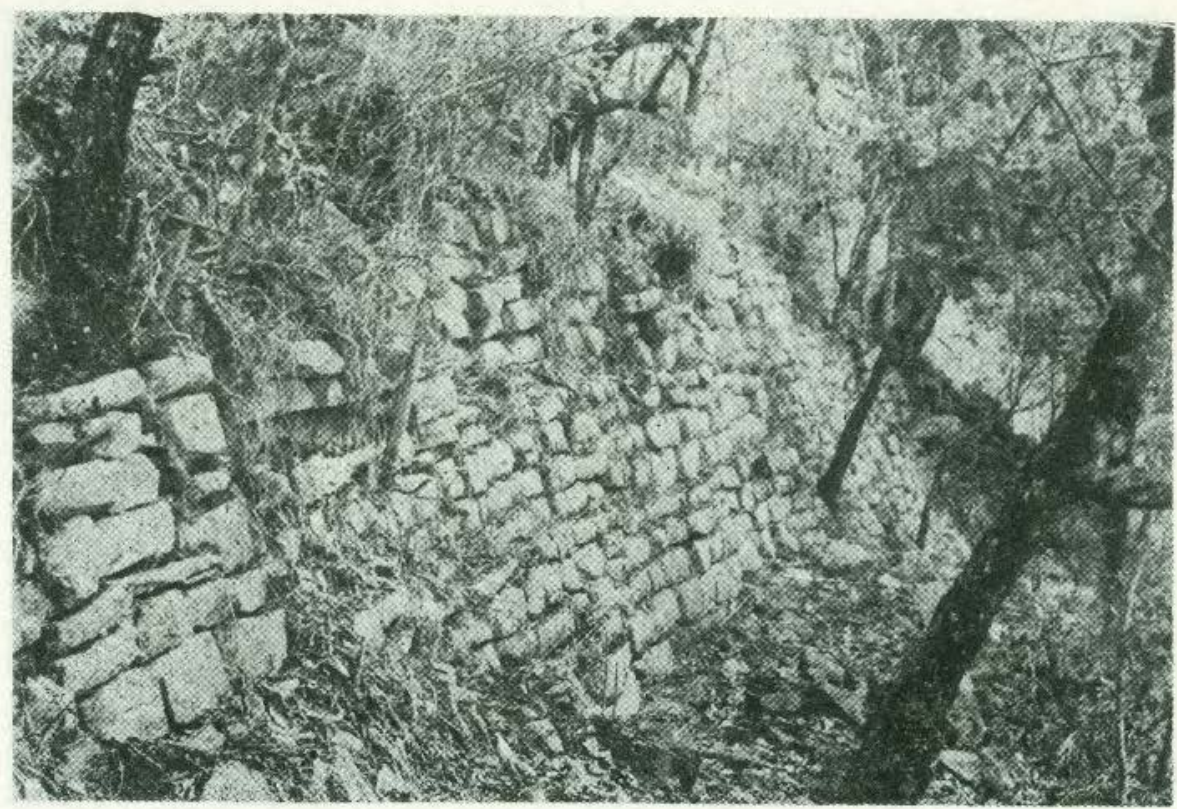

Lámina 20.

Estudios de Cultura Maya. Vol. XIV, 1982

Instituto de Investigaciones Filológicas/

Centro de Estudios Mayas, UNAM

http://www.iifilologicas.unam.mx/estculmaya/ 


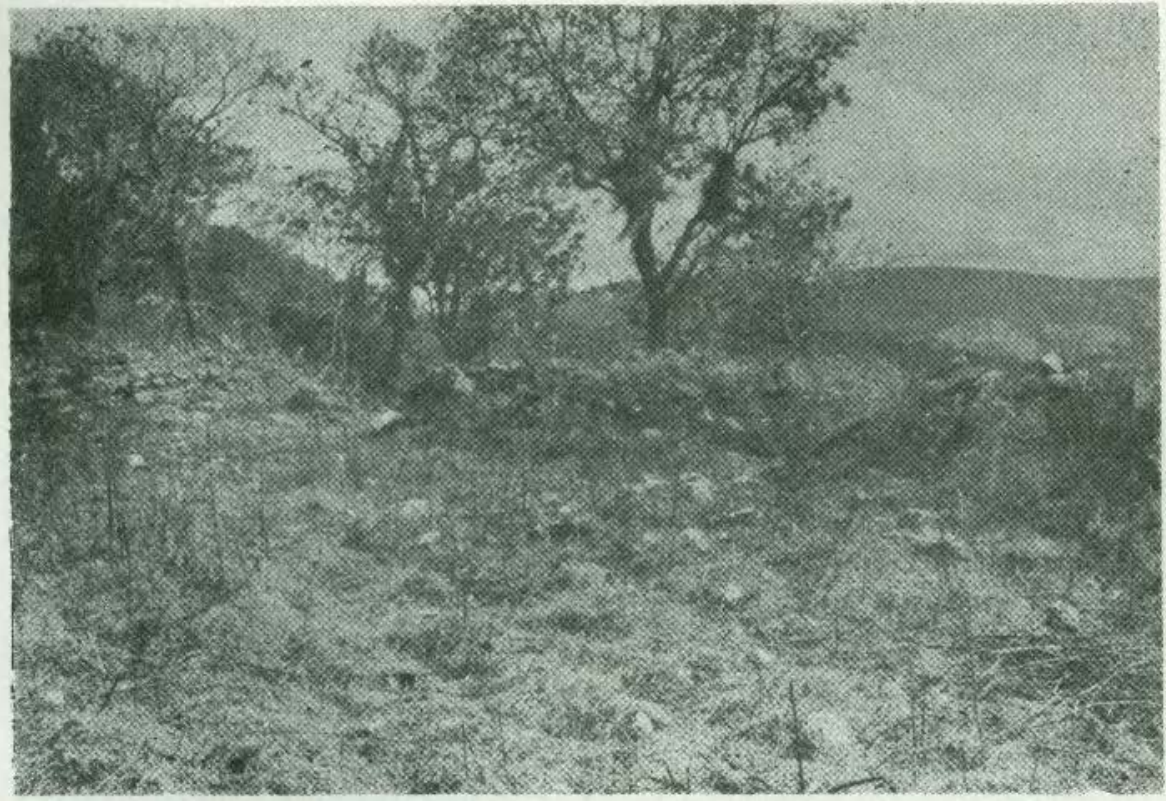

Lámina 21. Pequeños basamentos de piedras labradas al este del juego de pelota. MAR-II-1.

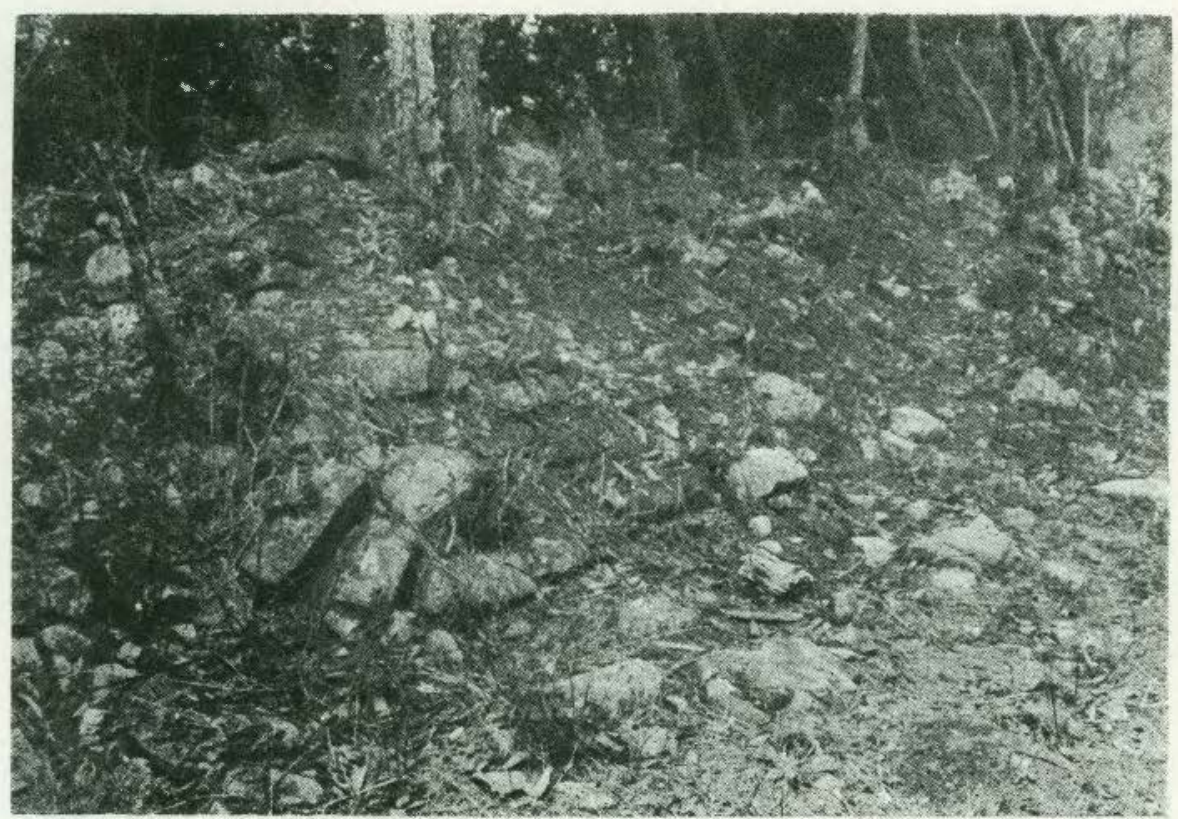

Lámina 22. Vista del cuerpo norte del juego de pelota en MAR-II-1. Se pueden apreciar restos de la banqueta. 


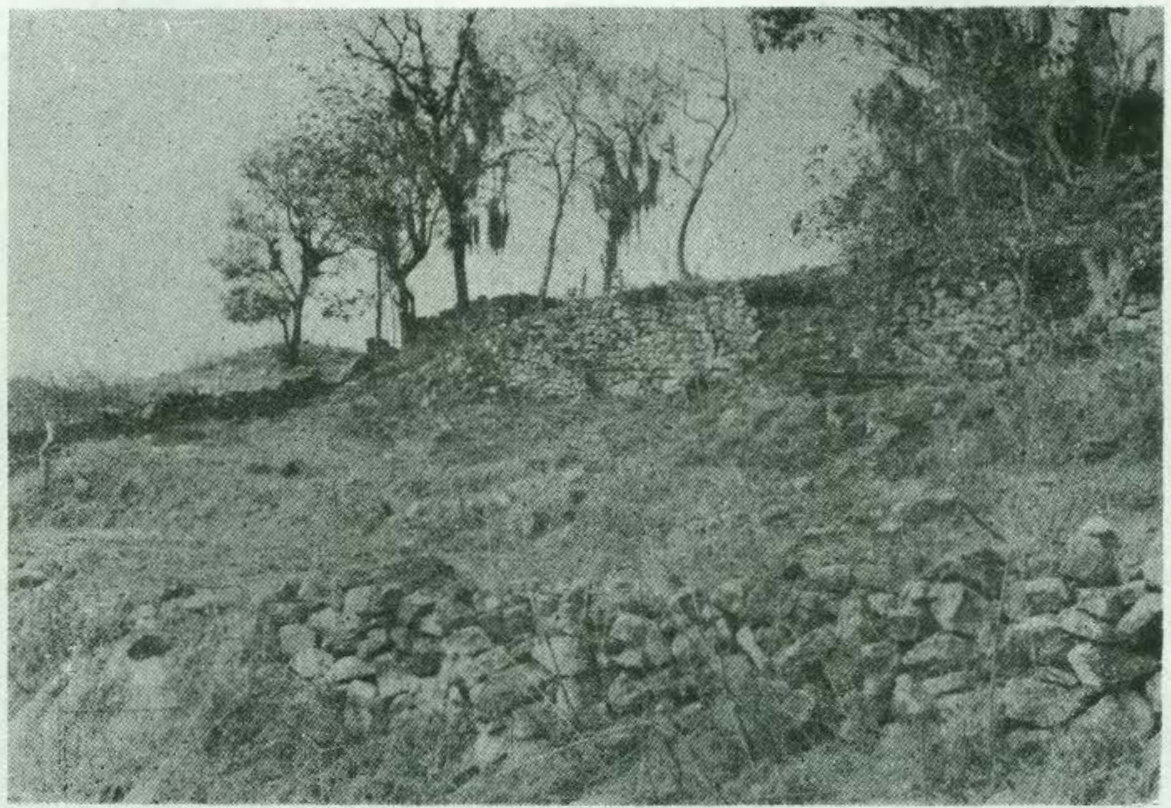

Lámina 23. Muros originales en el lado norte del juego de pelota en el sitio Najlem.

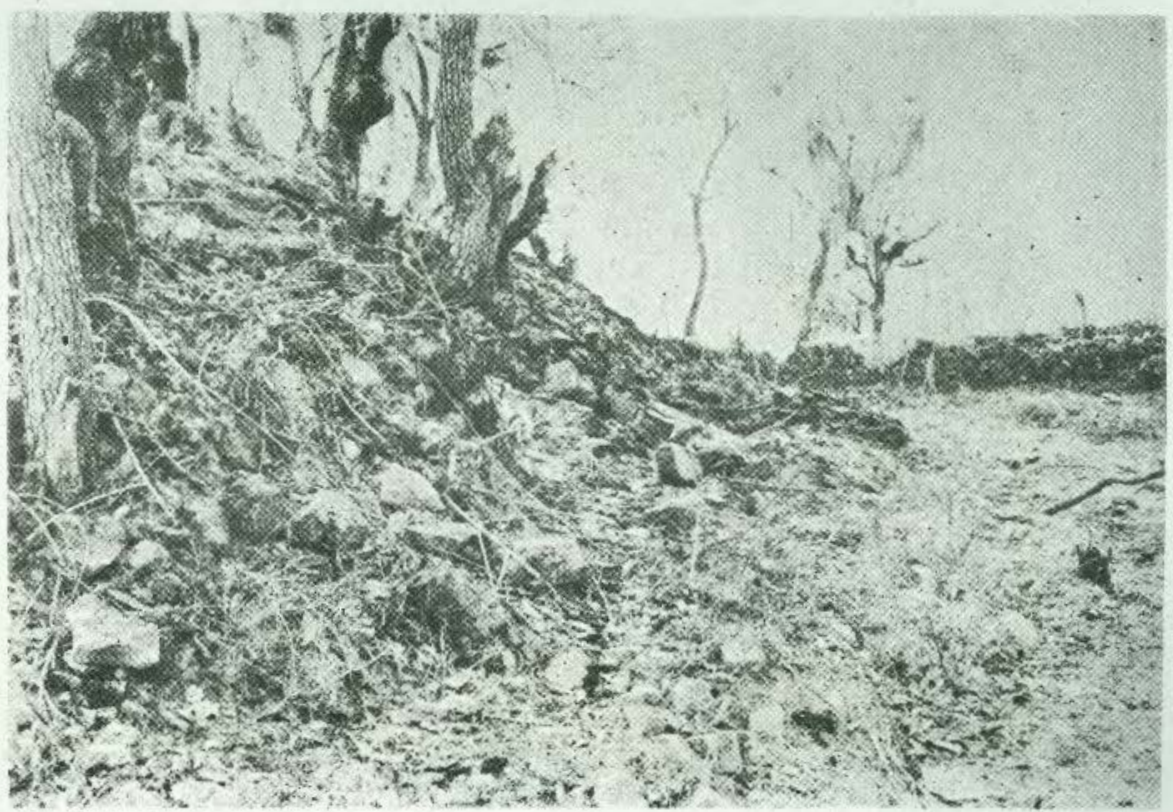

Lámina 24. Vistas de la cancha del juego de pelota. MAR-II-1. 


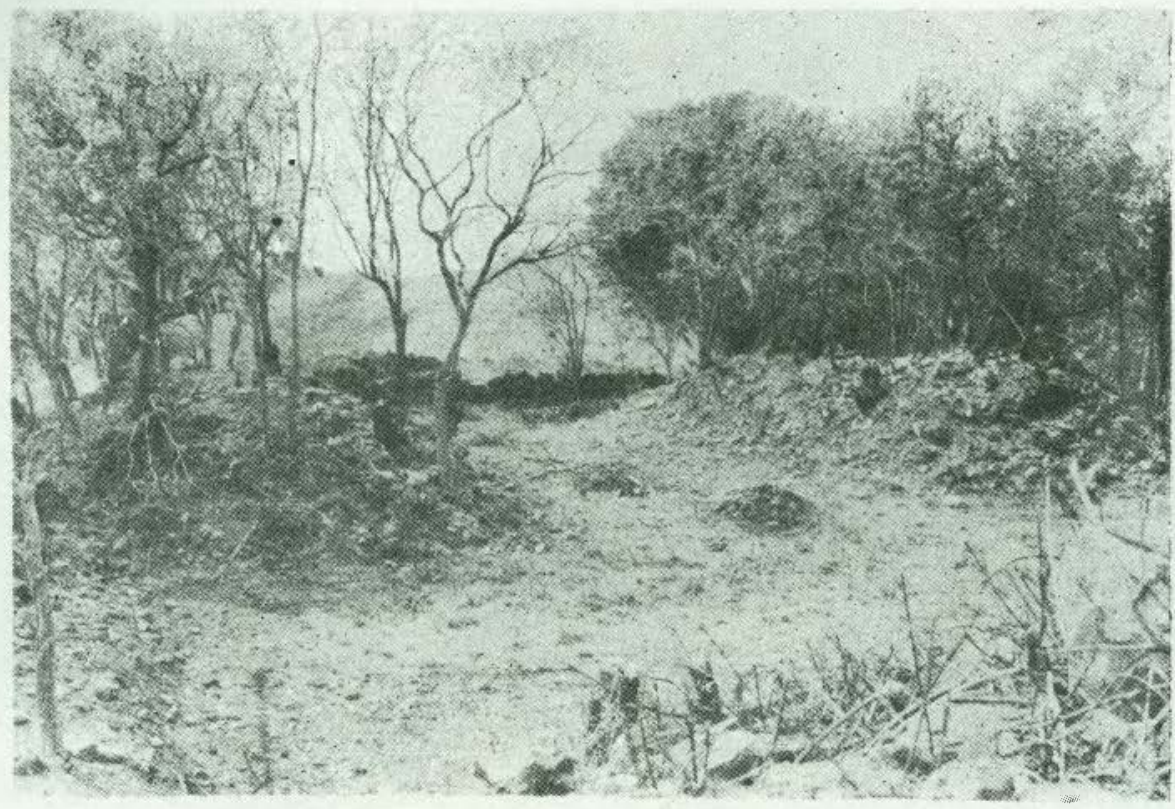

Lámina 25.

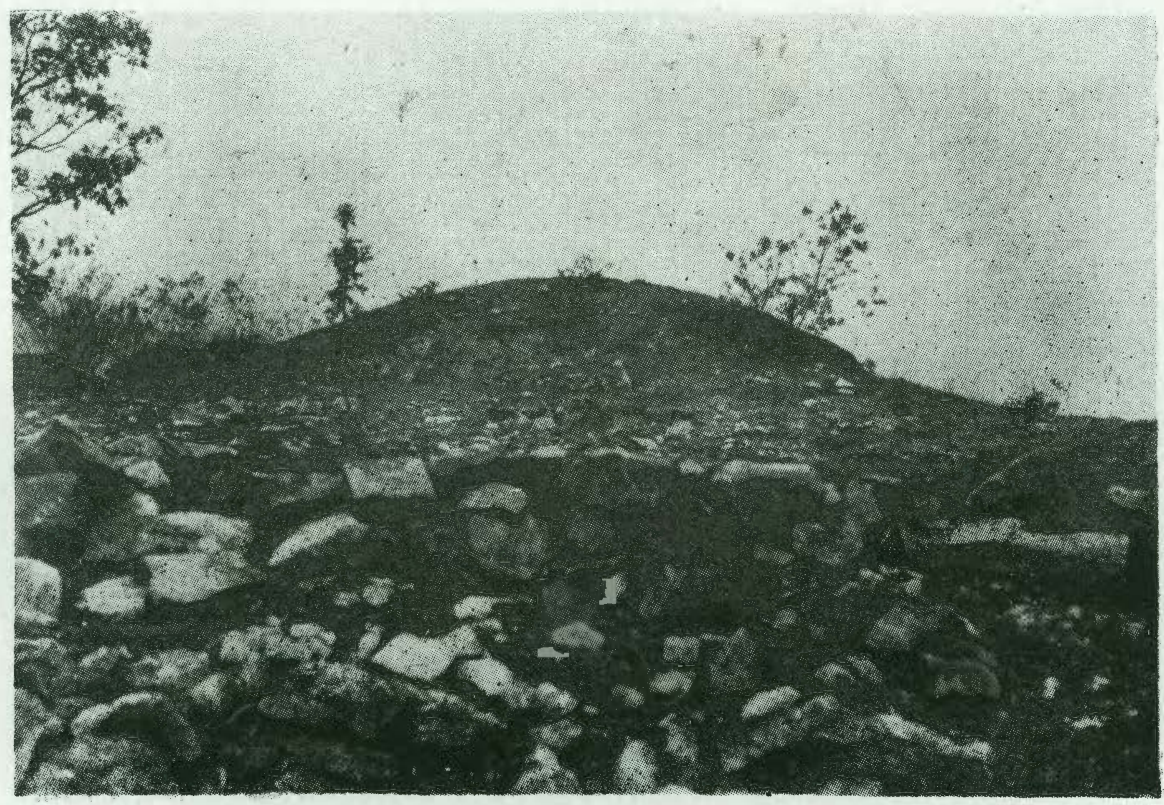

Lámina 26. Vista del sitio MAR-II-7.

Estudios de Cultura Maya. Vol. XIV, 1982

Instituto de Investigaciones Filológicas/

Centro de Estudios Mayas, UNAM 


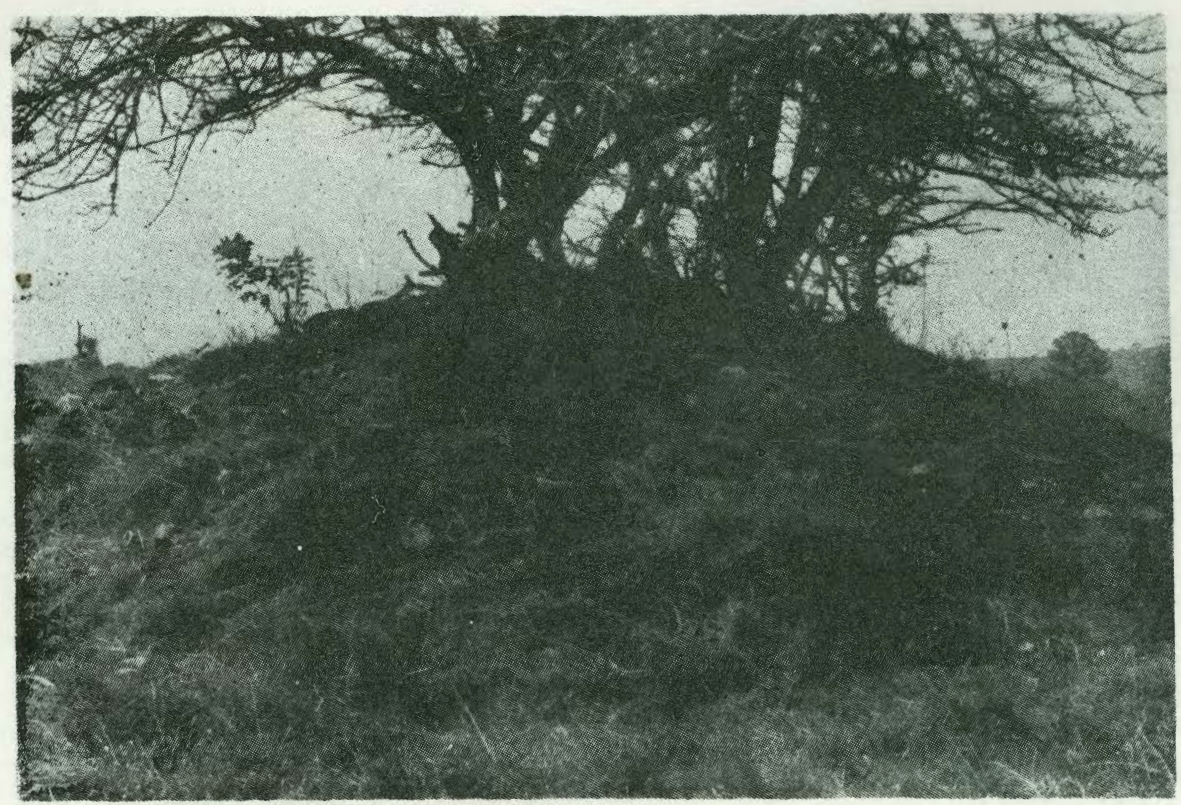

Lámina 27. Vista de un montículo en MAR-II-6.

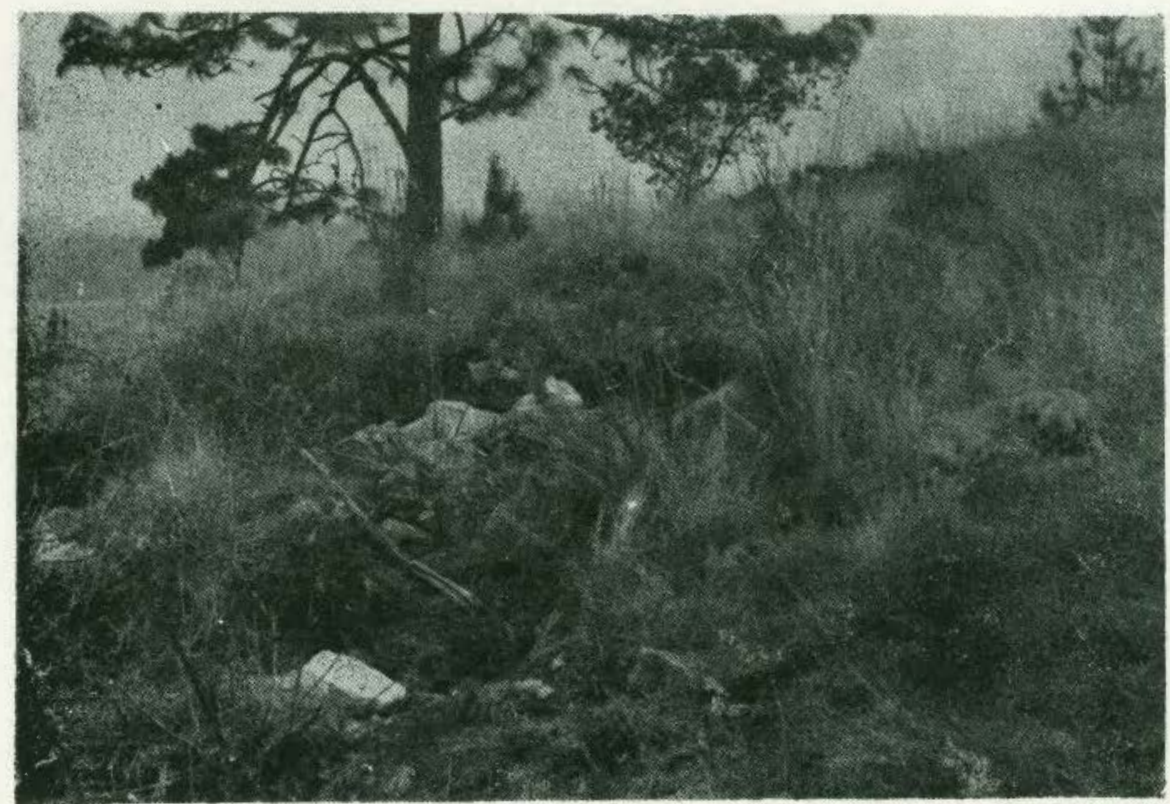

Lámina 28. Vista de un saqueo en el grupo principal de MAR-II-6.

Estudios de Cultura Maya. Vol. XIV, 1982

Instituto de Investigaciones Filológicas/

Centro de Estudios Mayas, UNAM 


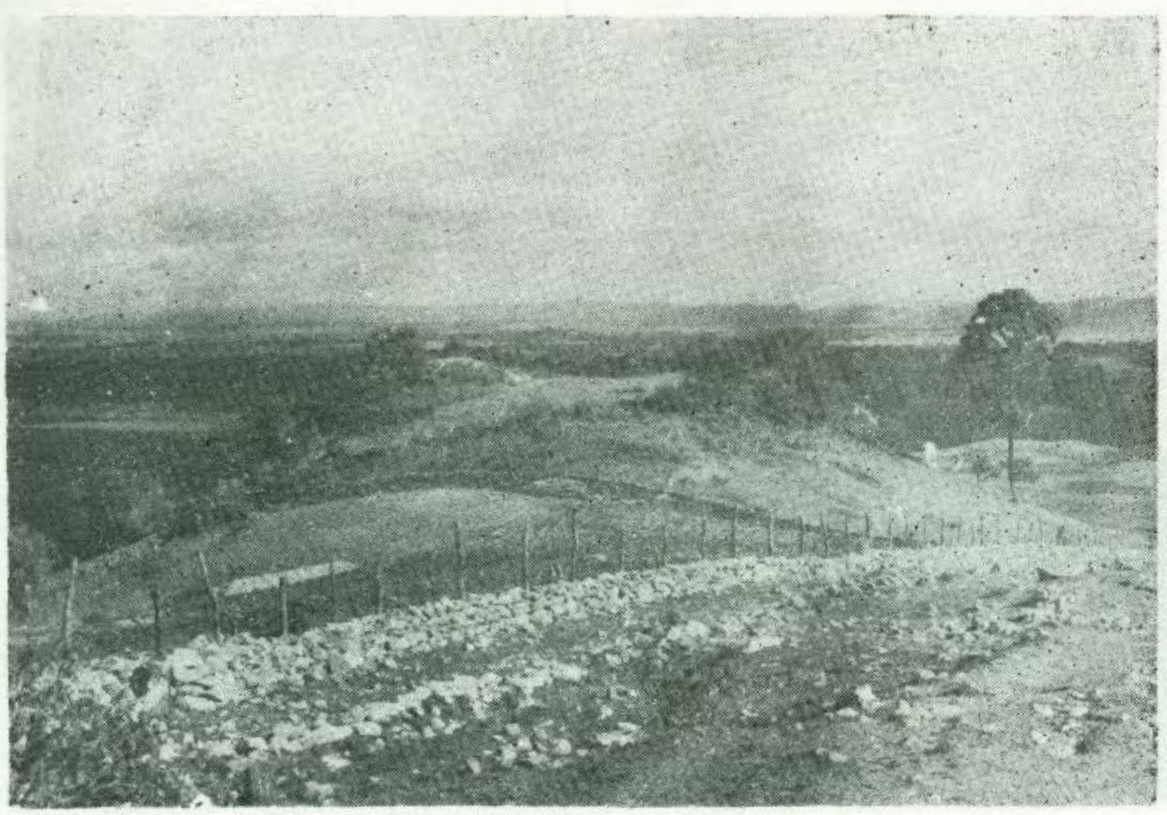

Lámina 29. Vista del grupo III en MAR-II-8.

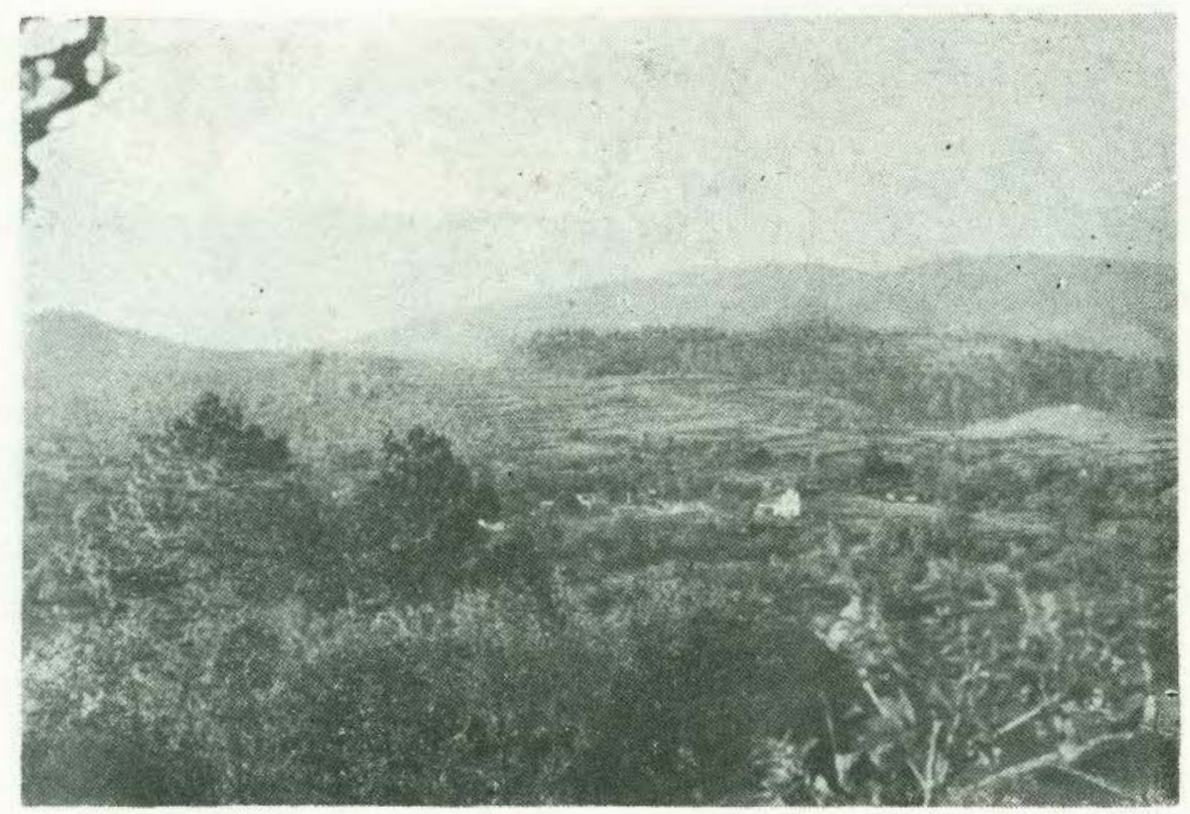

Lámina 30. Vista de las terrazas en el sitio Tehuan Huitz.

Estudios de Cultura Maya. Vol. XIV, 1982

Instituto de Investigaciones Filológicas/

Centro de Estudios Mayas, UNAM

http://www.iifilologicas.unam.mx/estculmaya/ 


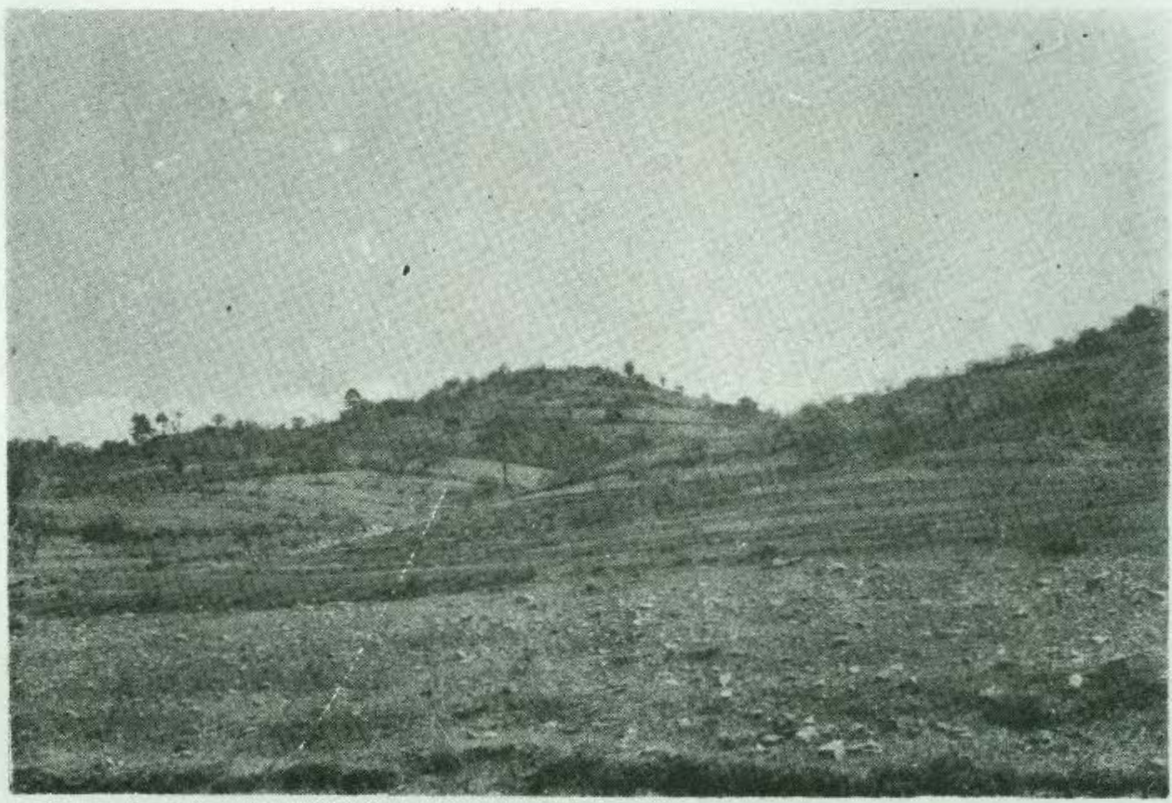

Lámina 31. Vista de las terrazas en MAR-II-4.

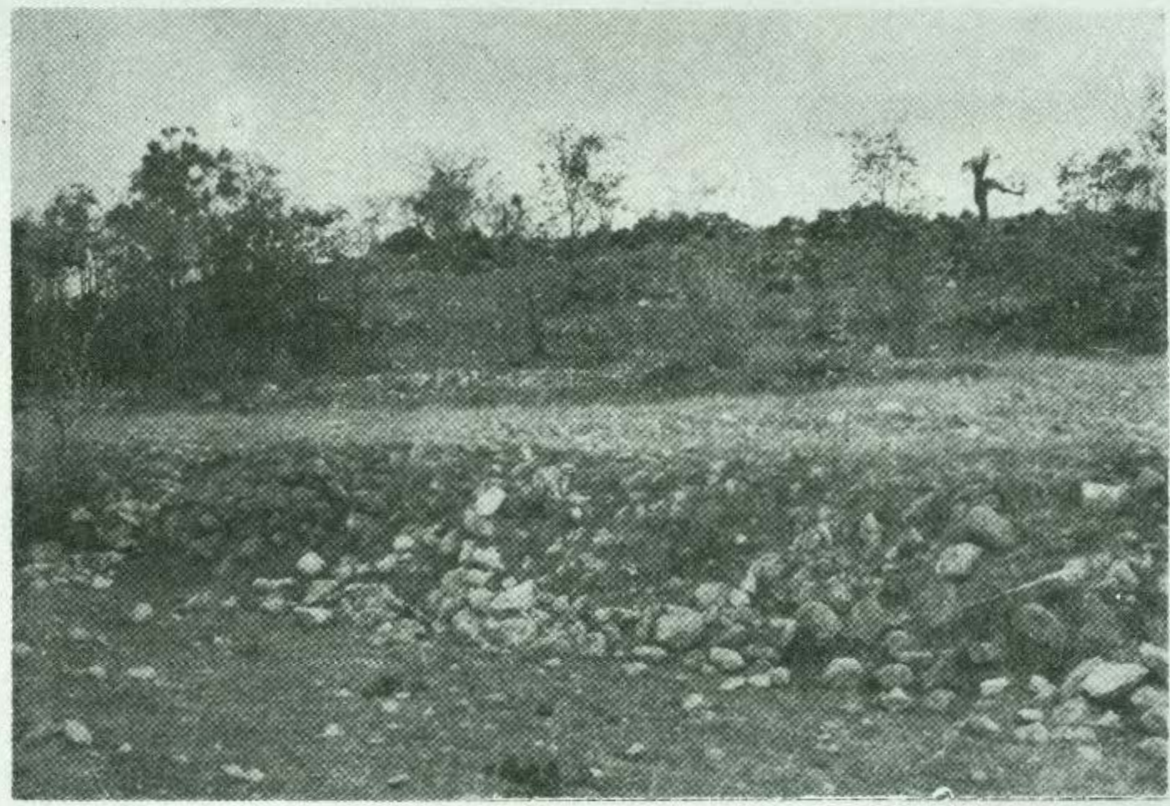

Lámina 32. Vista de una terraza en la parte interior del cerro Juan en MAR-II-4. 


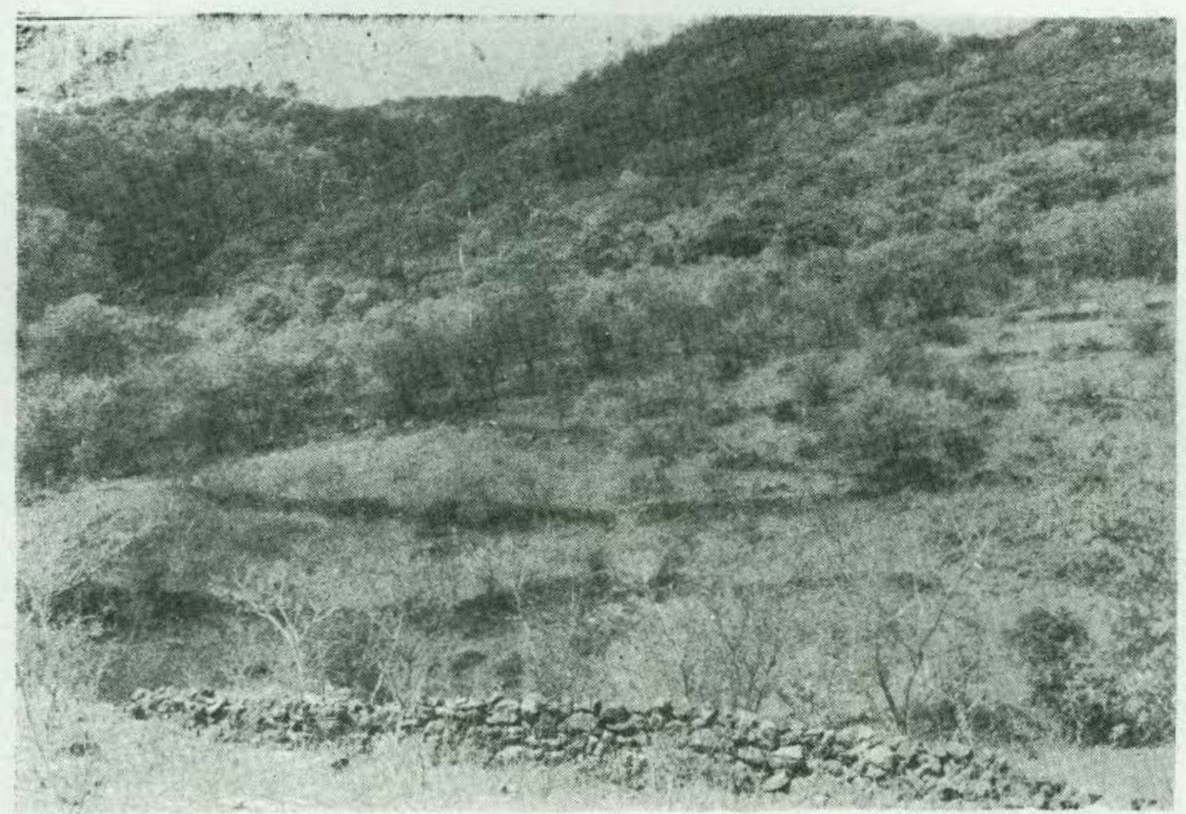

Lámina 33. Vista de terrazas habitacionales al sur del sitio Najlem MAR-II-1.

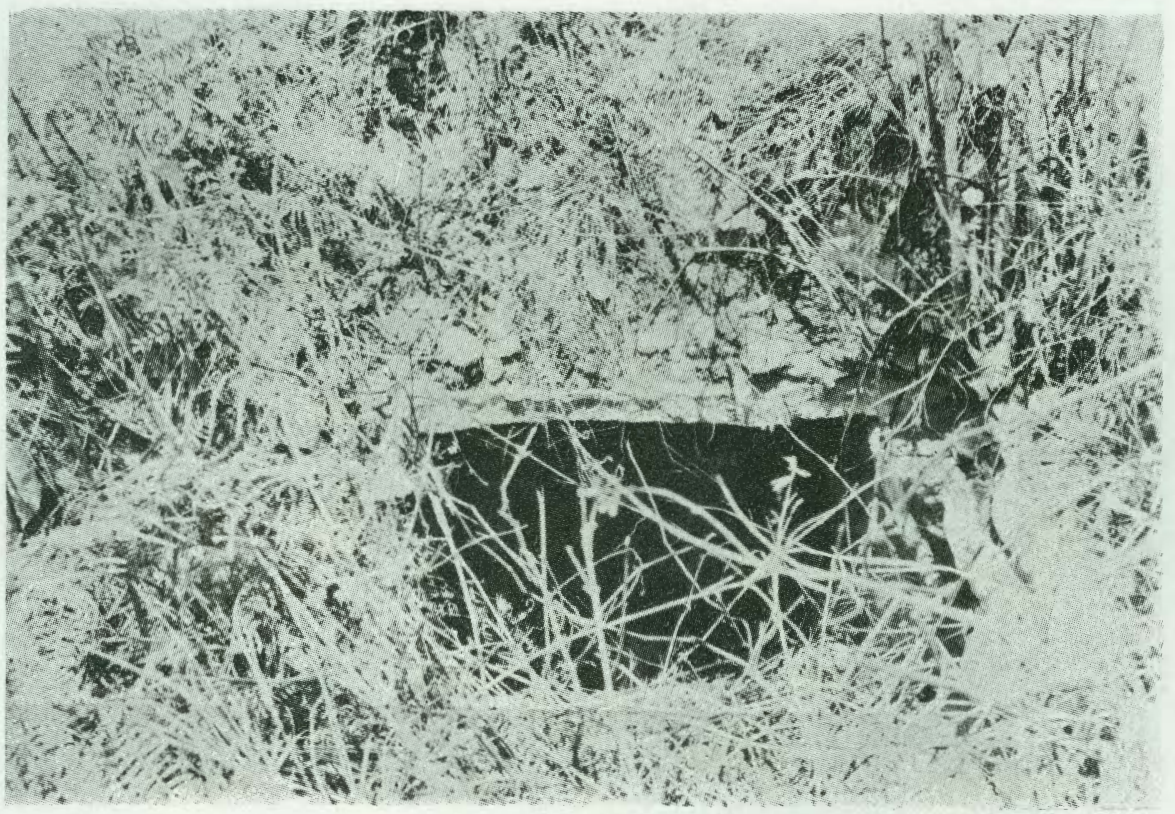

Lámina 34. Vista de una tumba de piedras labradas y tapa de losas grandes en MAR-II-4. 


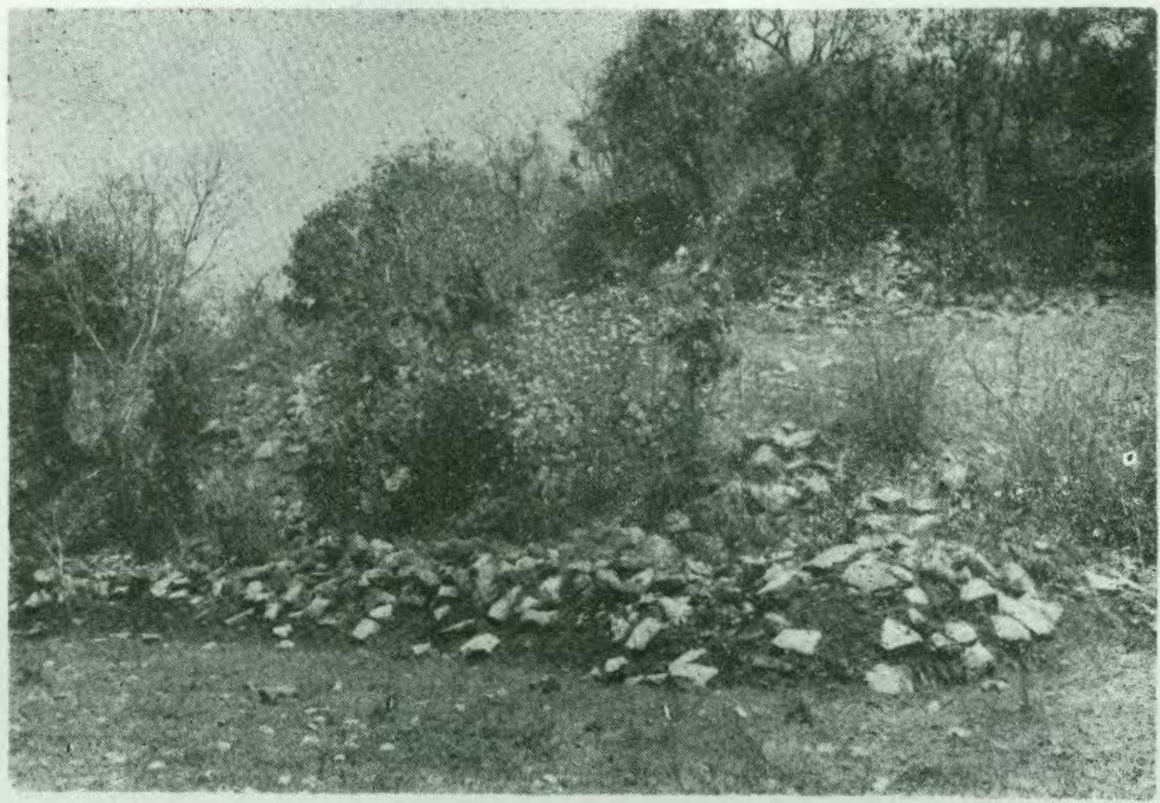

Lámina 35. Restos de una terraza que tiene dos chultunes.

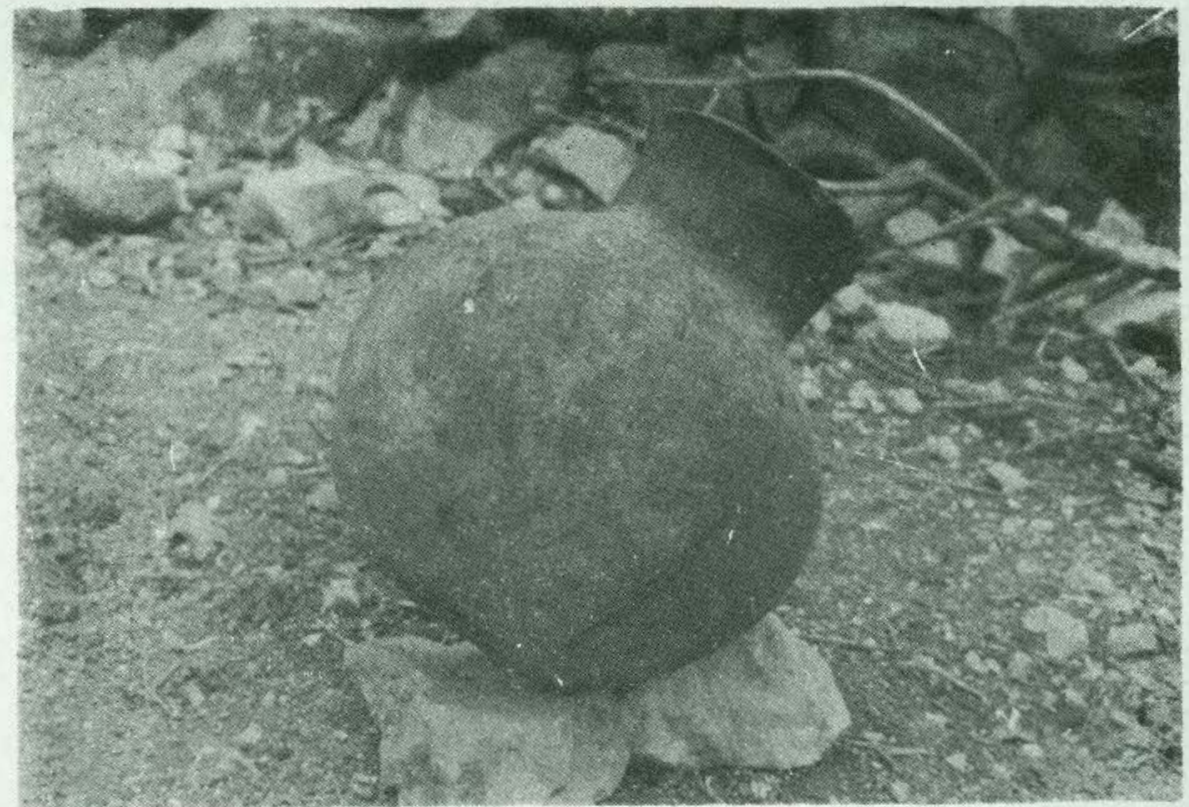

Lámina 36. Tinaja procedente de un saqueo en los chultunes de la fotografía anterior. 


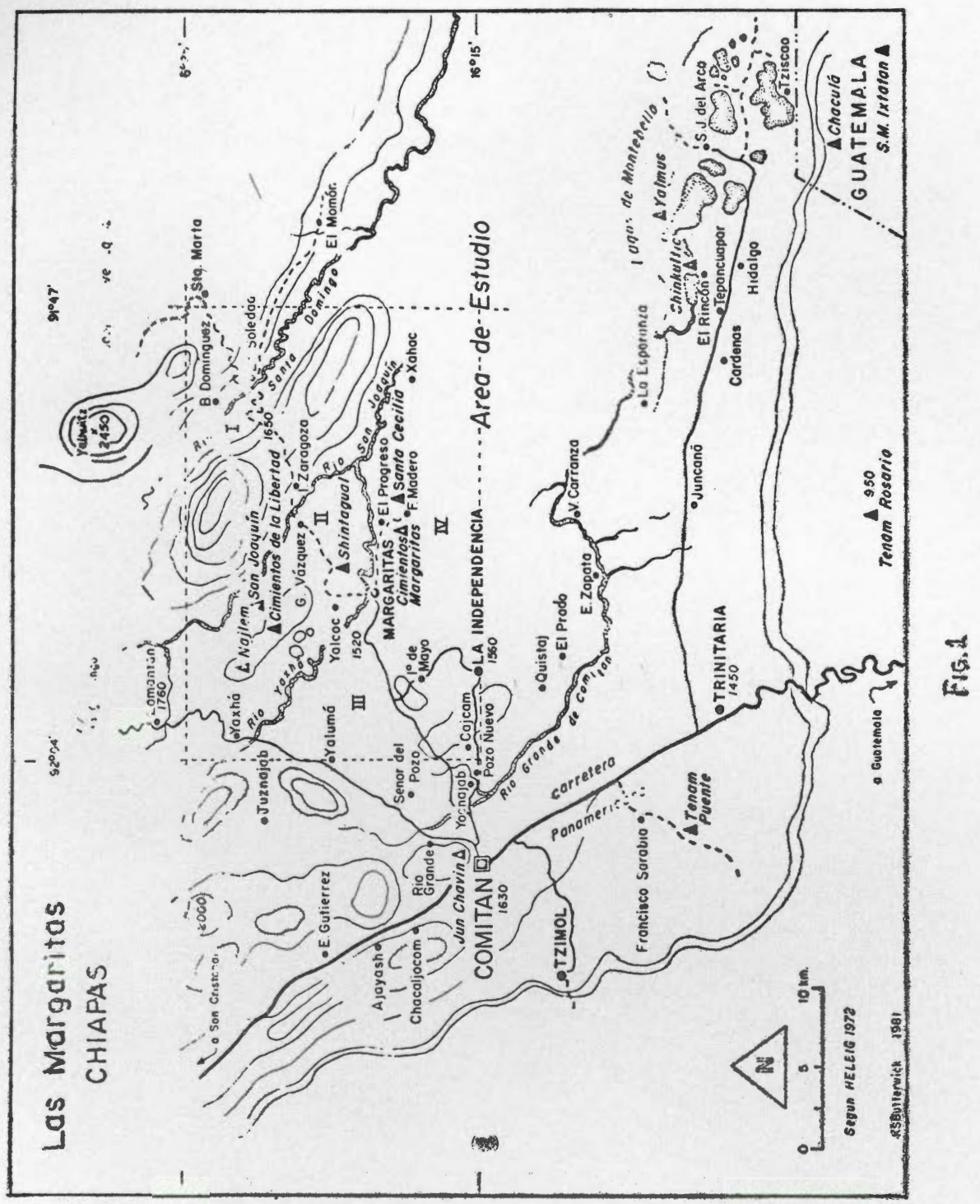




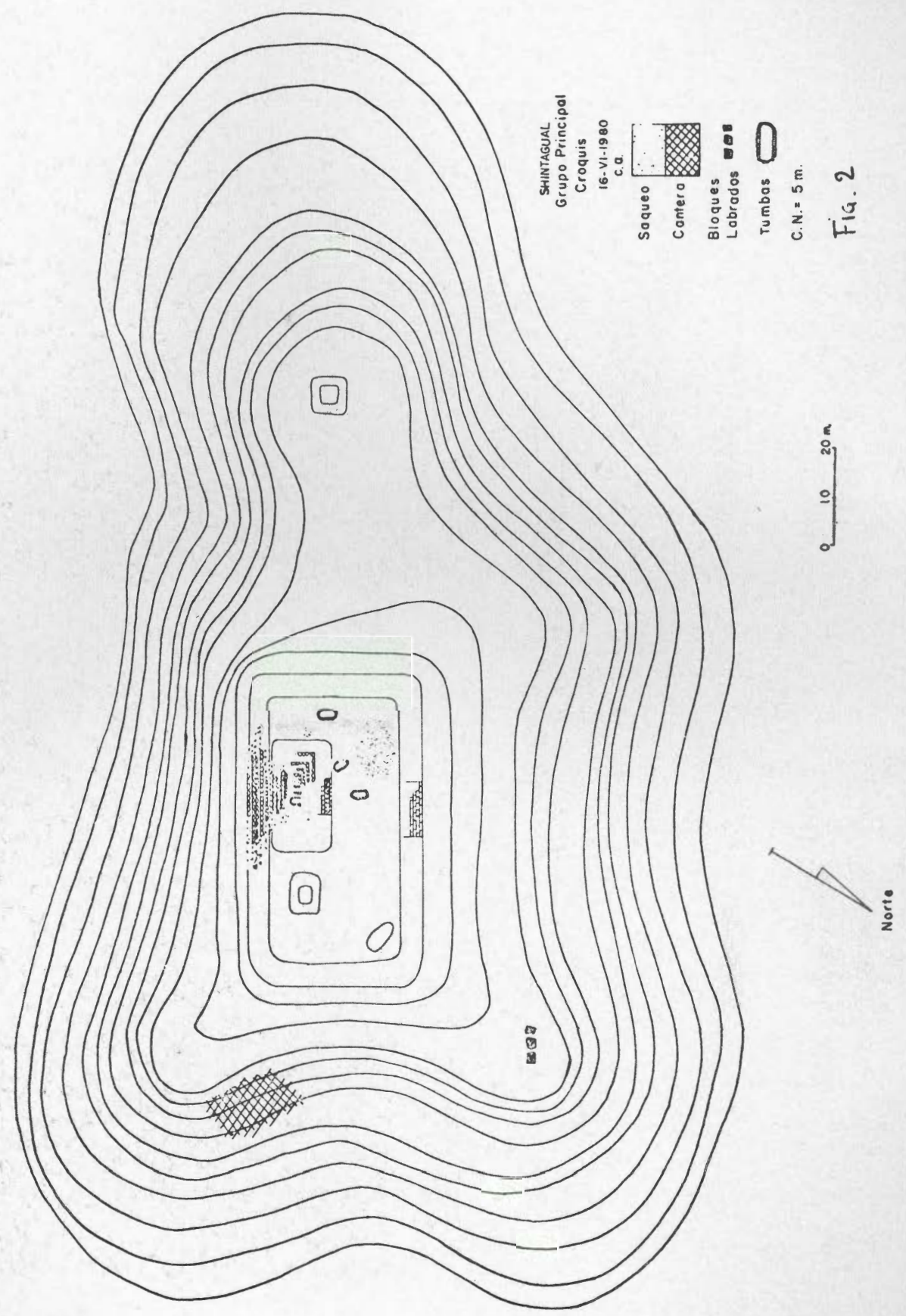

Estudios de Cultura Maya. Vol. XIV, 1982 


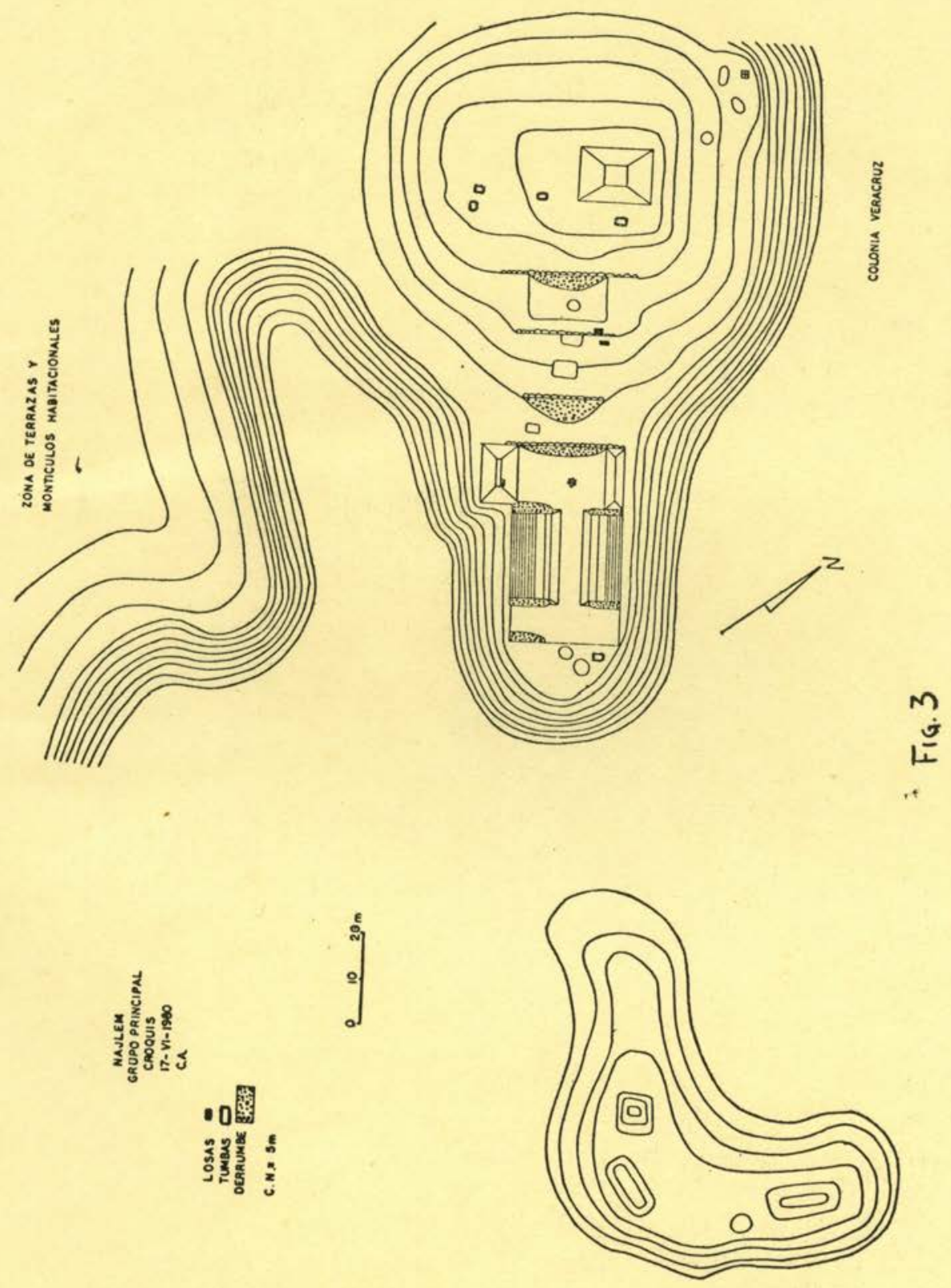

Fig. 3 